Future Combat Systems Program

\title{
Functional Decomposition of Modeling and Simulation Terrain Database Generation Process
}

Using Integration Definition for Function Modeling (IDEFØ)

Valerie Raybold Yakich and J. David Lashlee 


\section{Functional Decomposition of Modeling and Simulation Terrain Database Generation Process}

Using Integration Definition for Function Modeling (IDEFØ)

Valerie Raybold Yakich

Lockheed Martin

Simulation, Training and Support

Advanced Simulation Center

Bellevue, WA

J. David Lashlee

Topographic Engineering Center

U.S. Army Engineer Research and Development Center

Office of Technical Directors

Alexandria, VA

Approved for public release; distribution is unlimited.

Prepared for U.S. Army Future Combat Systems

Washington, DC 


\begin{abstract}
The construction of terrain databases is a complex and dynamic procedure. Every terrain database addresses a unique set of simulation federate needs and data availability. This report documents the conceptual procedure as implemented by Lockheed Martin Simulation, Training, and Support and decomposes terrain database construction using the Integration Definition for Function Modeling (IDEFØ). This report includes sufficient detail to conceptually describe the process and provide a foundation for discussion of new and existing terrain database construction efforts among stakeholders with varying levels of technical expertise.
\end{abstract}

DISCLAIMER: The contents of this report are not to be used for advertising, publication, or promotional purposes. Citation of trade names does not constitute an official endorsement or approval of the use of such commercial products. All product names and trademarks cited are the property of their respective owners. The findings of this report are not to be construed as an official Department of the Army position unless so designated by other authorized documents. 


\section{Executive Summary}

Modeling and Simulation (M\&S) is a rapidly growing sector of both the Army and Department of Defense. On 16 J uly 2007, the U.S. House of Representatives unanimously passed House Resolution 487, declaring M\&S a national critical technology that provides unparalleled advancements in American competitiveness and develops innovative ways to protect our homeland and our Warfighters.

Two of the most important M\&S key thrust areas are (1) credibly modeling military systems and Soldiers and (2) developing realistic environmental representations, including terrain databases. While the former is typically performed by system developers and integrators, the latter is an important part of the Topographic Engineering Center (TEC) primary mission, which is to provide the Warfighter with superior knowledge of the battlefield through the research, development, and application of the Topographic, Imagery, and Geospatial sciences.

Over the past decade, TEC has developed and maintained an expertise in generating correlated Visual and Constructive M\&S Terrain Databases for Computer Generated Forces applications. Today, TEC is a J oint Semi-Automated Forces simulation federate with mature capabilities for dynamic terrain and weather simulation and the rendering of troop movements in three dimensions, which are needed for distributed testing, training, and experimentation applications.

TEC's current M\&S capability is the cumulative product of two decades of experience in M\&S terrain scenario generation, development, and archive. Its role as a primary provider and distributor of M\&S terrain databases is a logical extension of its geospatial core competencies and consistent with its role as an Army Geospatial Knowledge Center. Simulation Engineers at TEC have developed a worldwide M\&S terrain database containing high fidelity terrain insets for strategic areas of interest. These data are distributed to U.S. Armed Services from the largest M\&S runtime terrain database archive in the nation, via the Defense Modeling and Simulation Office's Master Environmental Library web portal.

The purpose of this report is to document the M\&S terrain generation process implemented at TEC using the DoD Architecture Framework compliant Integration Definition for Function Modeling. The scope is limited to creation of correlated Visual (OpenFlight) and Compact Terrain Databases. While written from the viewpoint of J oint Forces Command simulation support, the tools and techniques summarized herein are directly applicable to supporting current and future Army M\&S requirements. 


\section{Contents}

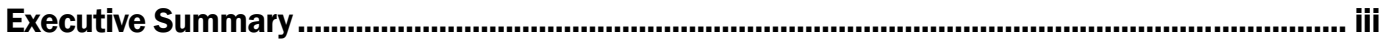

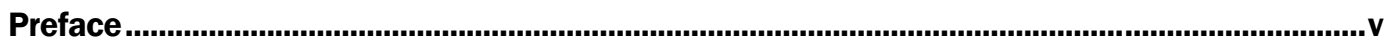

1 Introduction

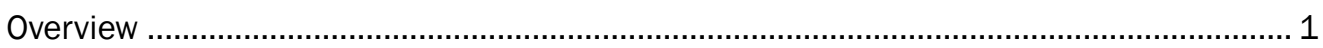

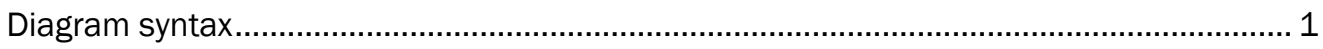

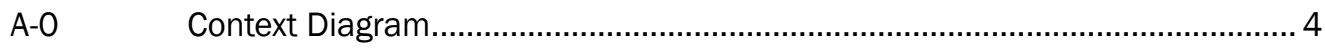

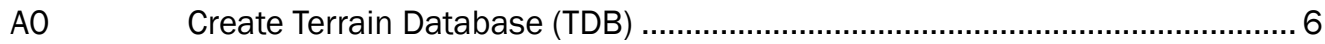

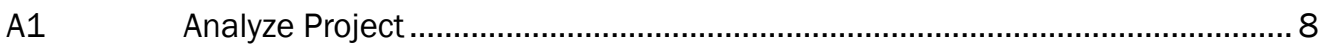

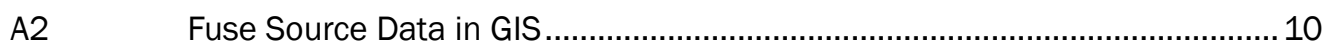

A21 Acquire Data 12

A22 Import Data 14

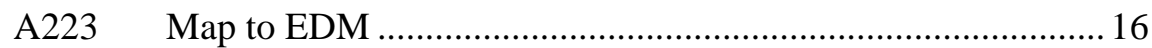

A24 Intensify 20

A25 Create Repository $\quad 22$

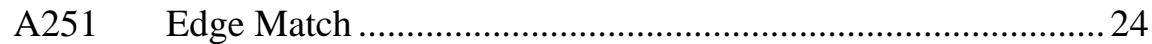

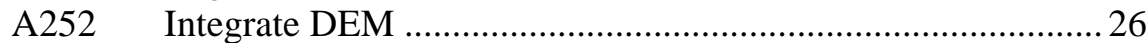

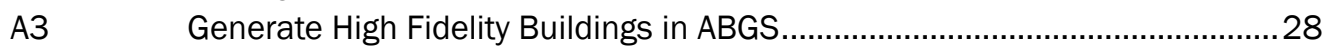

A4 Create Surface in Terrain Tools .............................................................30

A41 Generate Cell(s) 33

A43 Impress Features $\quad 35$

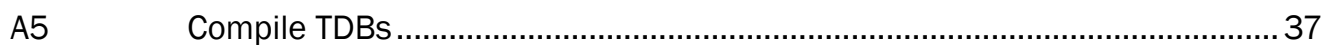

A51 Compile CTDB 39

A52 Compile Visual Database $\quad 41$

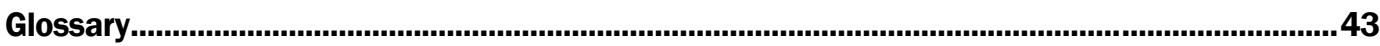

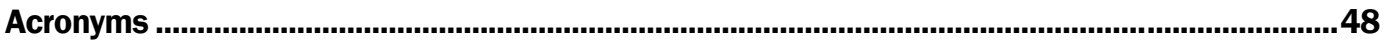

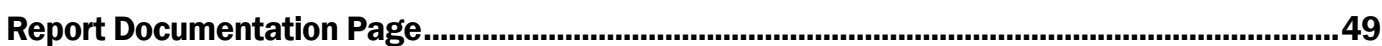




\section{Preface}

This work was done for the Future Combat Systems (FCS) Combined Test Organization. The work was performed by the Office of Technical Directors, Topographic Engineering Center (TEC). Technical review was done by J uan Perez, TEC's Systems Division Chief.

The TEC Principal Investigator was Associate Technical Director Dr. J . David Lashlee. Michael Coley is the Technical Director for Systems. The Deputy Director of TEC is J oseph F. Fontanella. The TEC Director is Robert W. Burkhardt.

TEC is an element of the U.S. Army Engineer Research and Development Center (ERDC), U.S. Army Corps of Engineers. The Commander and Executive Director of ERDC is COL Gary E. J ohnston, and the Director of ERDC is Dr. J ames R. Houston. 


\section{Introduction}

\section{Overview}

The construction of terrain databases is a complex and dynamic procedure. Every terrain database addresses a unique set of simulation federate needs and data availability. This report documents the conceptual procedure as implemented by Lockheed Martin Simulation, Training, and Support and decomposes terrain database construction using the Integration Definition for Function Modeling (IDEFØ). This report includes sufficient detail to conceptually describe the process and provide a foundation for discussion of new and existing terrain database construction efforts among stakeholders with varying levels of technical expertise.

\section{Diagram syntax}

NOTE: Appropriate interpretation of diagrams within this report relies on an understanding of the IDEFØ modeling syntax and semantics. The draft IDEFØ standard is available from the National Institute of Standards and Technology (www.itt.nist.gov/fipspubs/idef02.doc).

The direction from which an arrow enters a function indicates the role of incoming data/ resources in the process. The inclusion of a sub-diagram identifier indicates that the function is decomposed to a higher level of detail in a subsequent node diagram.

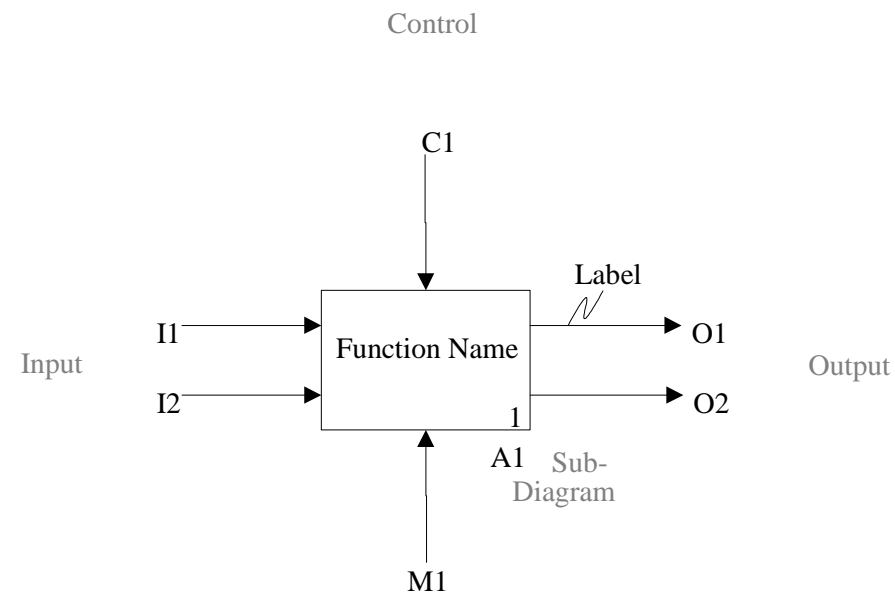


NOTE: This report includes one modification to IDEFØ: the use of color coded connecting lines. Red lines represent the required minimal path for creation of correlated Compact Terrain Database (CTDB) and visual database (for ModStealth). Gray lines have been applied occasionally to aid distinctions when tracing connections among processes. 


\section{IDEFØ Node Tree}

\section{A-0 Context Diagram}

A0 Create Terrain Database

A1 Analyze Project

A11 Identify/ Analyze Existing Data/ Resources

A12 Analyze Data Collection/Creation Resources

A13 Reconcile/ Prioritize Federate Needs

A14 Scope the Project

A15 Create/ Adopt Environmental Data Model (EDM)

A2 Fuse Source Data in GIS

A21 Acquire Data

A211 Download/ Request Media

A212 Purchase

A213 Copy

A214 Extract Relevant Datasets

A215 Evaluate Data Quality

A22 Import Data

A221 Reformat for GIS

A222 Convert Spatial Reference Frame (SRF)

A223 Map to EDM

A2231 Create Mapping Rules

A2232 Convert Features/Attributes/Values

A2233 Convert Geometry

A2234 Validate Domains

A2235 Calculate Values/ Apply Defaults

A224 Create Image Catalogs

A23 Deconflict

A231 Analyze Conflicts

A232 Trump/ Delete Conflicts by Rank

A233 Shift/Reroute Features

A234 Simulate New Features

A235 Conflate Attributes

A24

Intensify Features

A241 Analyze Geospatial Repository

A242 Prioritize Intensification Needs

A243 Extract/ Digitize Features/ Attributes

A25

Simulate/ Derive Features/Attributes

A251 Edge Match

A2511 Clip by Play Box

A2512 Clip by Area of Interest (AOI)

A2513 Connect Linear Features

A2514 Merge Areal Features

A252 Integrate DEM

A2521 Filter DEM

A2522 Clip by Play Box

A2523 Clip by AOI

A2524 Seam DEM

A253 Project to Geodetic
A254 Create Empty Repository

A255 Load Features

A256 Load Image Catalogs

A3 Generate High Fidelity Buildings in ABGS

Configure Attribution Rules

A32 Derive Stochastic Values

A33 Identify Primary Entrance

A34 Create Semantic Floorplans

A35 Create Physical Building Models

A4 Create Surface in Terrain Tools

A41 Generate Cell(s)

A411 Clip to Cell Boundaries

A412 Derive Features

A413 Derive Attributes

A414 Assign Textures

A415 Index Features

A42 Seam DEM

A43 Impress Features

A431 Deconflict Coastline

A432 Expand Linear Features

A433 Adjust Surface Elevations

A44 Build TIN

A45 Convert to Target SRF

A46 Generate Patches

A5 Compile TDBs

A51 Compile CTDB

A511 Translate Surface

A512 Ground 2D Features

A513 Extrude Buildings

A514 Integrate 3D Features/ Models

A515 Generate Topology

A52 Compile Visual Database

A521 Translate Surface

A522 Ground 2D Features

A523 Extrude Buildings

A524 Integrate 3D Features/Models

A53 Analyze Results 


\section{A-0 Context Diagram}

As noted in the diagram below, the construction of a terrain database is controlled by federate needs, funding, and deadlines. These databases take incorporate and enhance available data. The entire process is accomplished through the mechanisms of a variety of tools and expertise. Subject matter experts assist in the selection, presentation, processing, and storage formats of terrain elements. The procedures identified in this report are not bound to specific geographic information system (GIS) or terrain processing tools; however, the U.S. Army Engineer Research and Development Center's Topographic Engineering Center (TEC) has traditionally implemented these functionalities with ArcGIS by Environmental Systems Research Institute (ESRI) and TerraTools by TerraSim, respectively. 


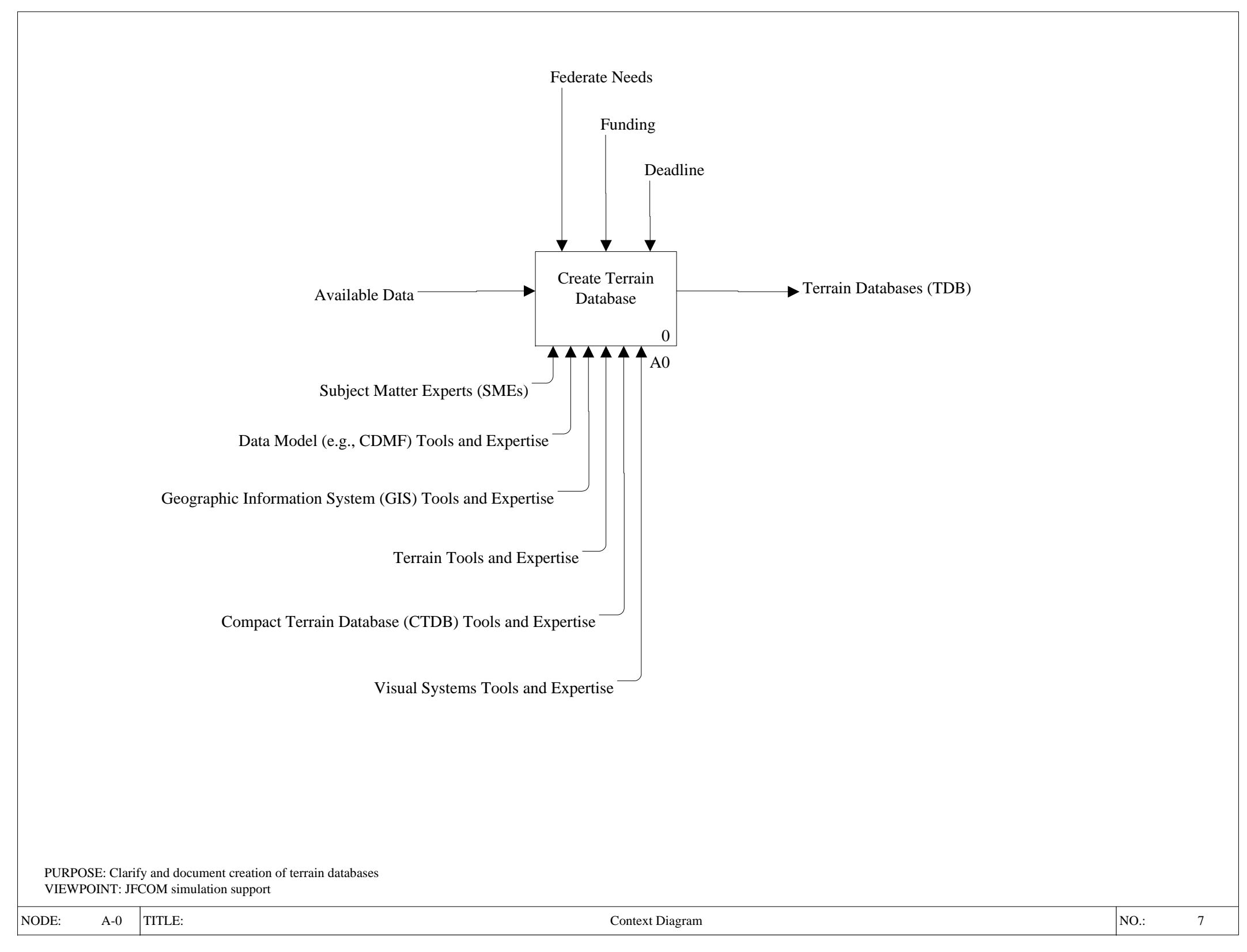




\section{A0 Create Terrain Database (TDB)}

The process of creating a terrain database requires five basic steps: project analysis, data fusion, building generation, surface creation, and compilation. These steps are documented to varying depths in the node tree depending upon the complexity of the step.

The deepest diagrams decompose Fuse Data Sources (A2). Data fusion is a complex process of integration and intensification that is highly variable depending upon the goals and source data for a given terrain database.

The Geospatial Repository is the set of all GIS data created during the data fusion process. It incorporates features, digital elevation models (DEM),

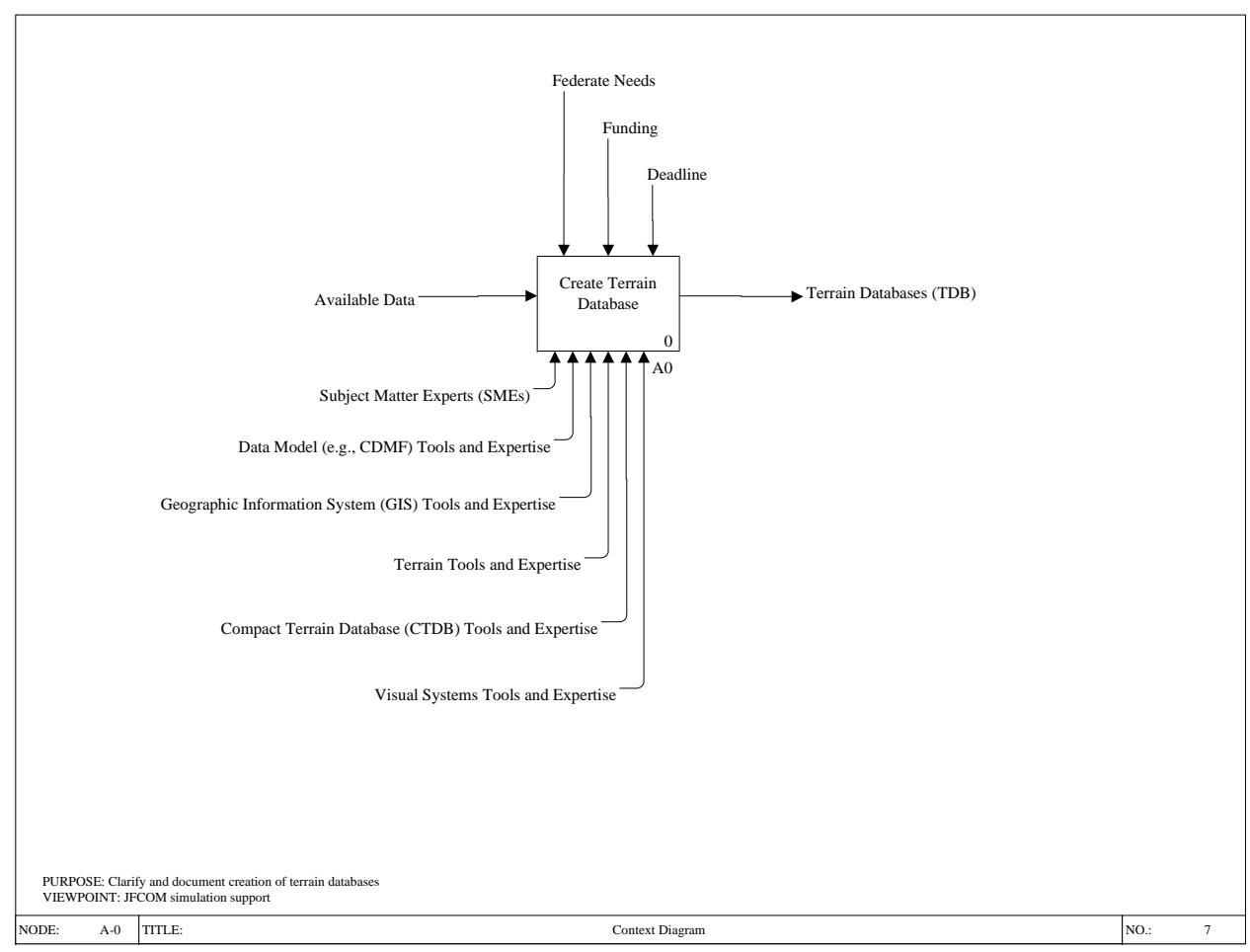
and, for most projects, imagery.

Although not performed for all TDBs, TEC has particular expertise in the generation of high-fidelity, geotypical buildings using geospecific building footprint locations. Compile TDBs (A5) has a shallow set of node diagrams describing the logical actions occurring during compilation; at TEC, compilation is a highly automated process. The validation of resultant databases feeds back into data fusion to iteratively improve TDBs quality.

NOTE: All functions within Fuse Source Data (A2) and Generate High Fidelity Buildings (A3) require GIS Tools and Expertise. All processes within Create Surface (A3) require Terrain Tools and Expertise. These tools and expertise will not be shown in lower level decompositions of A2, A3, and A4. In IDEFØ terminology, these mechanisms have been "tunneled out" as indicated by parentheses around the arrow heads. 


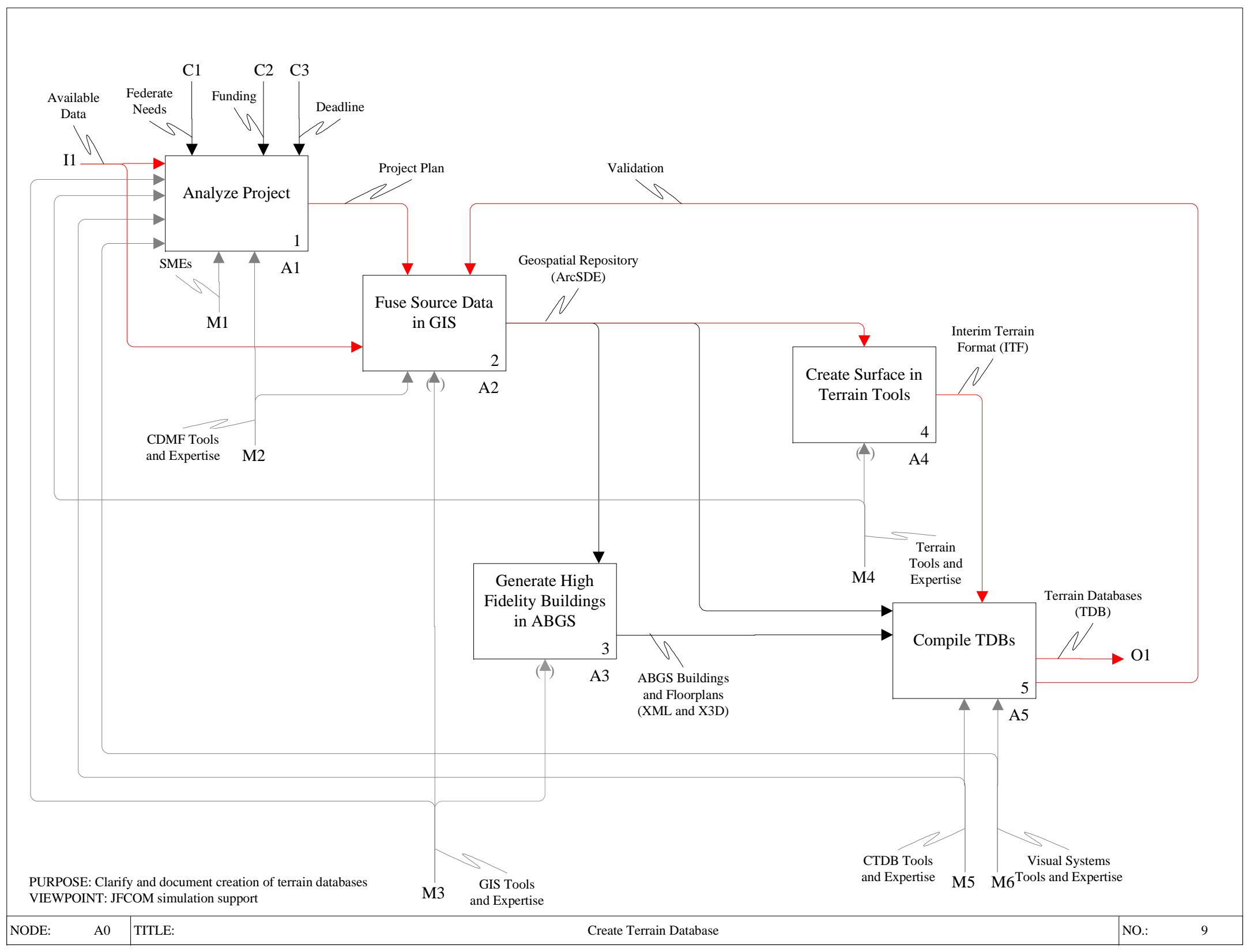




\section{A1 Analyze Project}

As with any endeavor, the stakeholders must first analyze a project in terms of available resources. For terrain database creation, these resources include: needs of federates participating in a simulation, available data, technology, funds and time.

The process of defining and prioritizing needs for a TDB is an iterative process and requires the cooperation of federates and terrain database creation experts.

The creation or adoption of Environmental Data Models (EDMs) is central to the TEC approach to terrain database creation. EDMs provide a machine-parsable method of describing data requirements. The Common Data Model Framework (CDMF) contains a

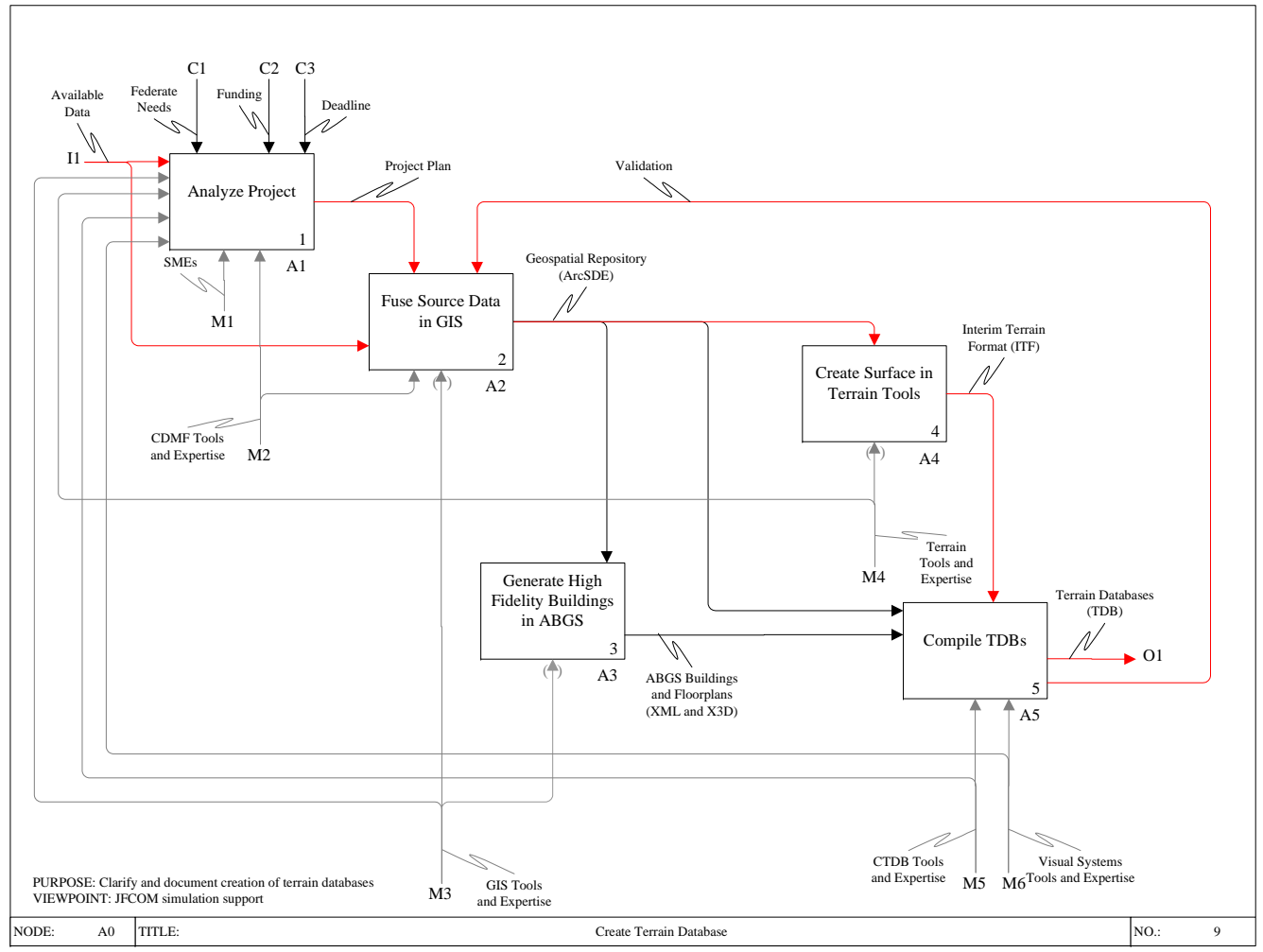
set of tools for creating and analyzing EDMs.

CDMF is a government-off-the-shelf technology designed and built by TEC.

NOTE: Diagrams throughout this report take advantage of the IDEFØ semantics for branching and joining arrows in which high level arrows can be viewed as pipelines or conduits and branching and joining may represent bundling or unbundling of data or objects relating to the functions being performed. For example, the Project Plan as depicted in A1 is composed of a schedule, a statement of work, and an EDM. (See pages 20 and 21 in the IDEFØ draft standard for a more thorough explanation of branching and joining.) 


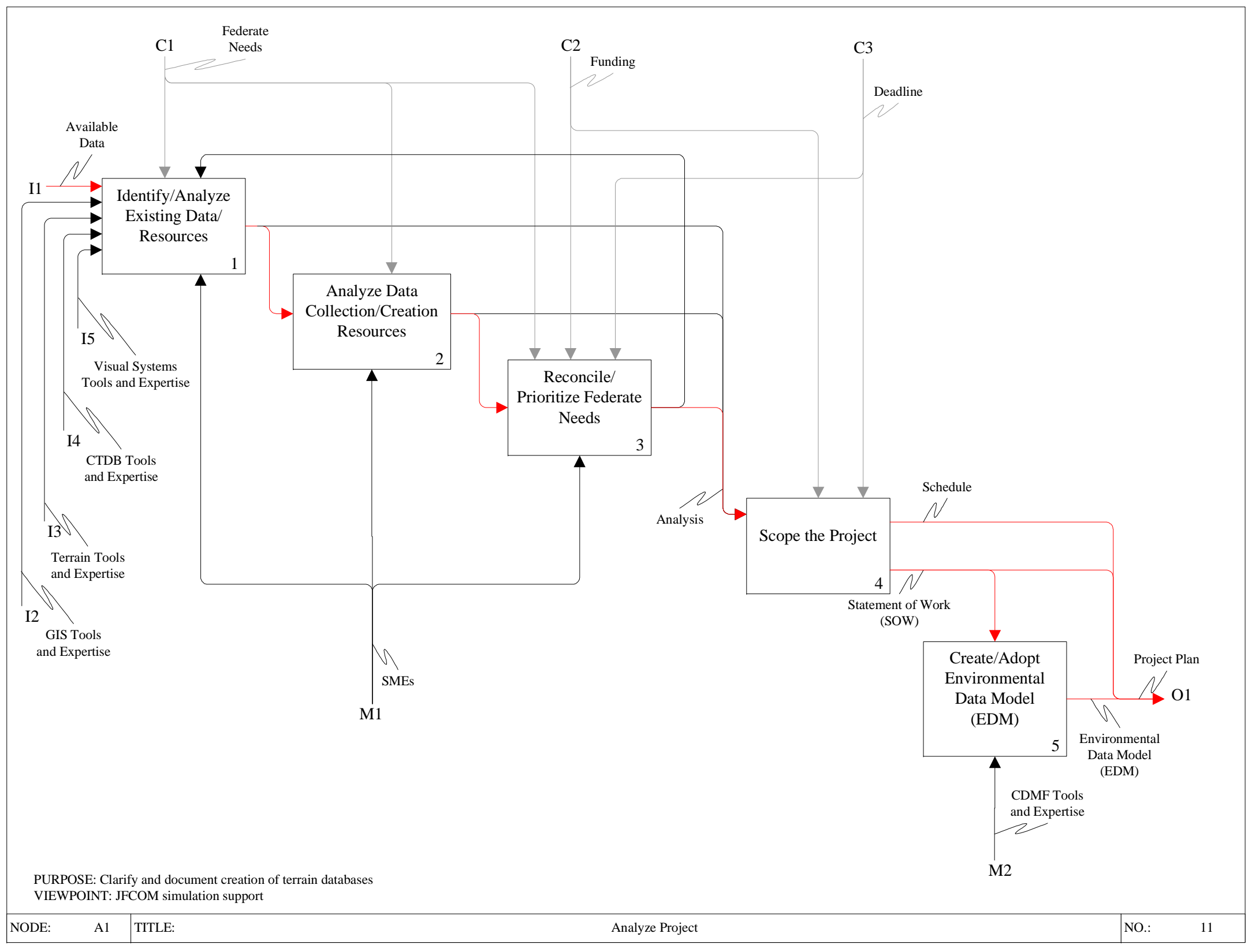




\section{A2 Fuse Source Data in GIS}

This diagram begins to break down the complexity of fusing data from varying sources, which have varying formats, schemas, resolution, extents, and quality.

All the functions within A2 require extensive use of GIS. Properly wielded, GIS tools have the power and functionality necessary to process spatial data logically and rationally. Relevant data must be acquired and imported to begin adding value through deconfliction and intensification efforts. The final step is to consolidate the resultant datasets into a repository.

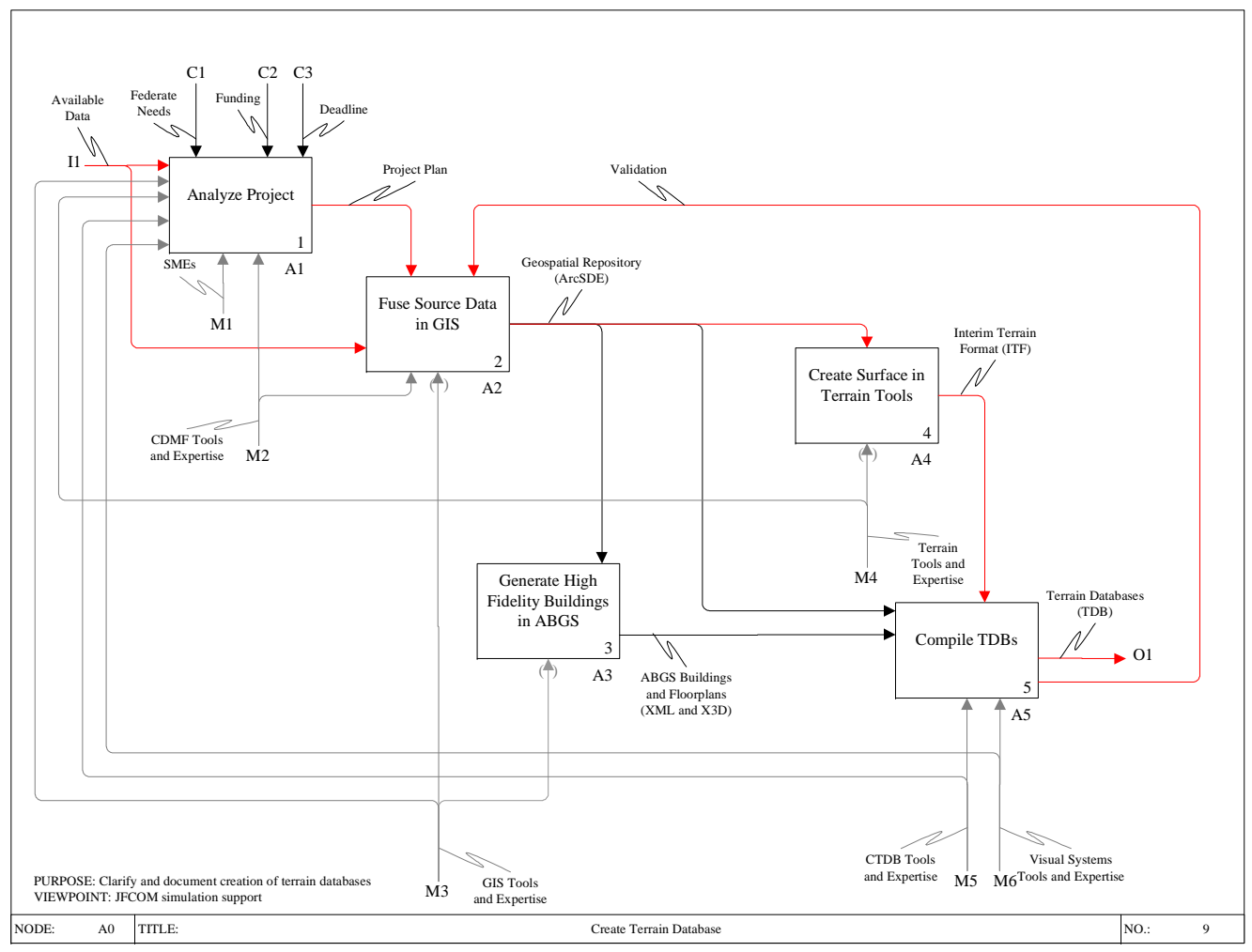




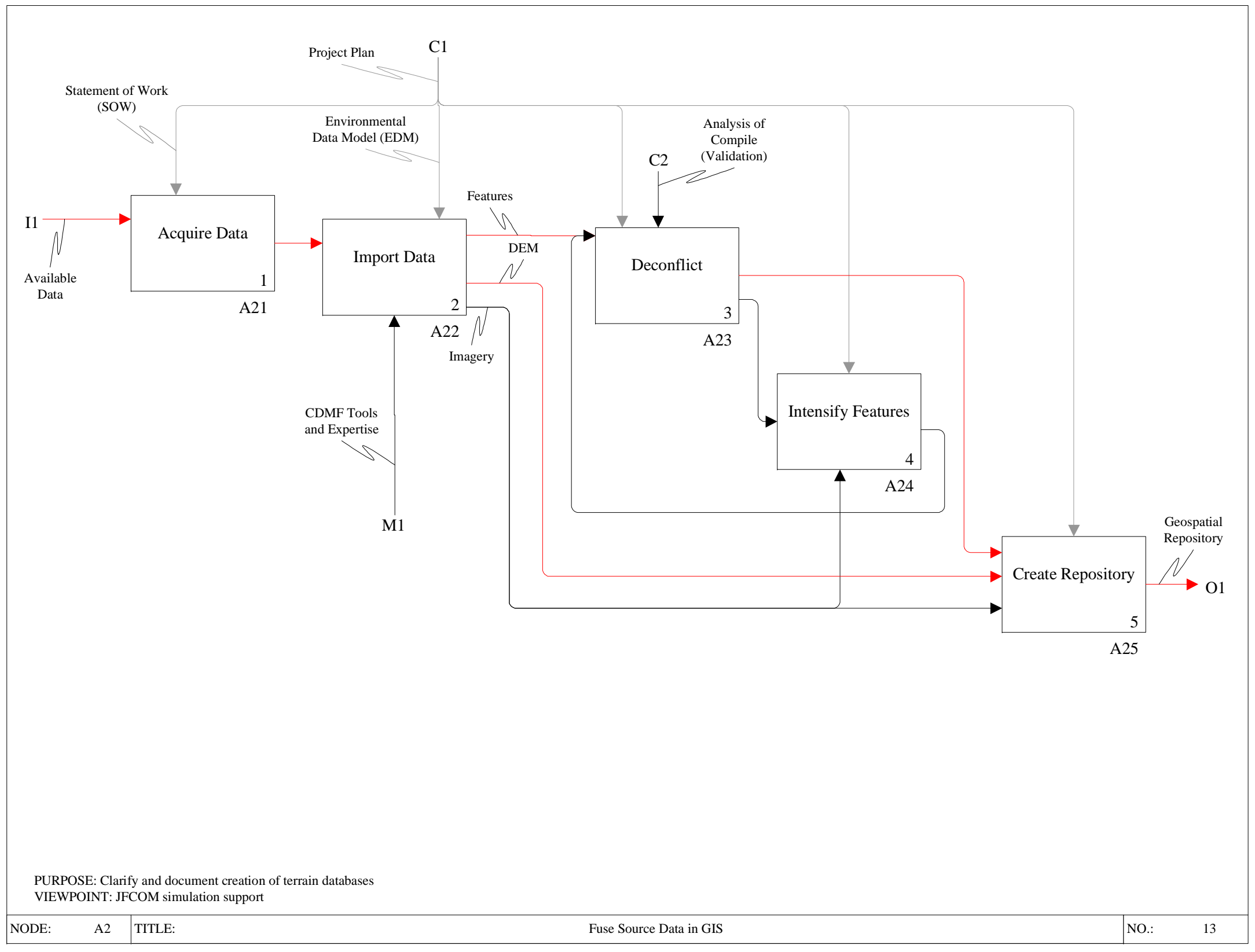




\section{A21 Acquire Data}

Acquisition of data can be time consuming. Historically, TEC has worked with government customers to acquire a variety of datasets. Access to such datasets often depends upon the customer's authority and/or ability to declassify existing data.

Datasets currently held by TEC, such as the worldwide low resolution data created for the Terrain Scenario Generation and Archiving (TSGA) project are readily available for integration into new TDBs.

In instances where a third-party vendor holds or can best create a data source, acquisition requires the purchase of

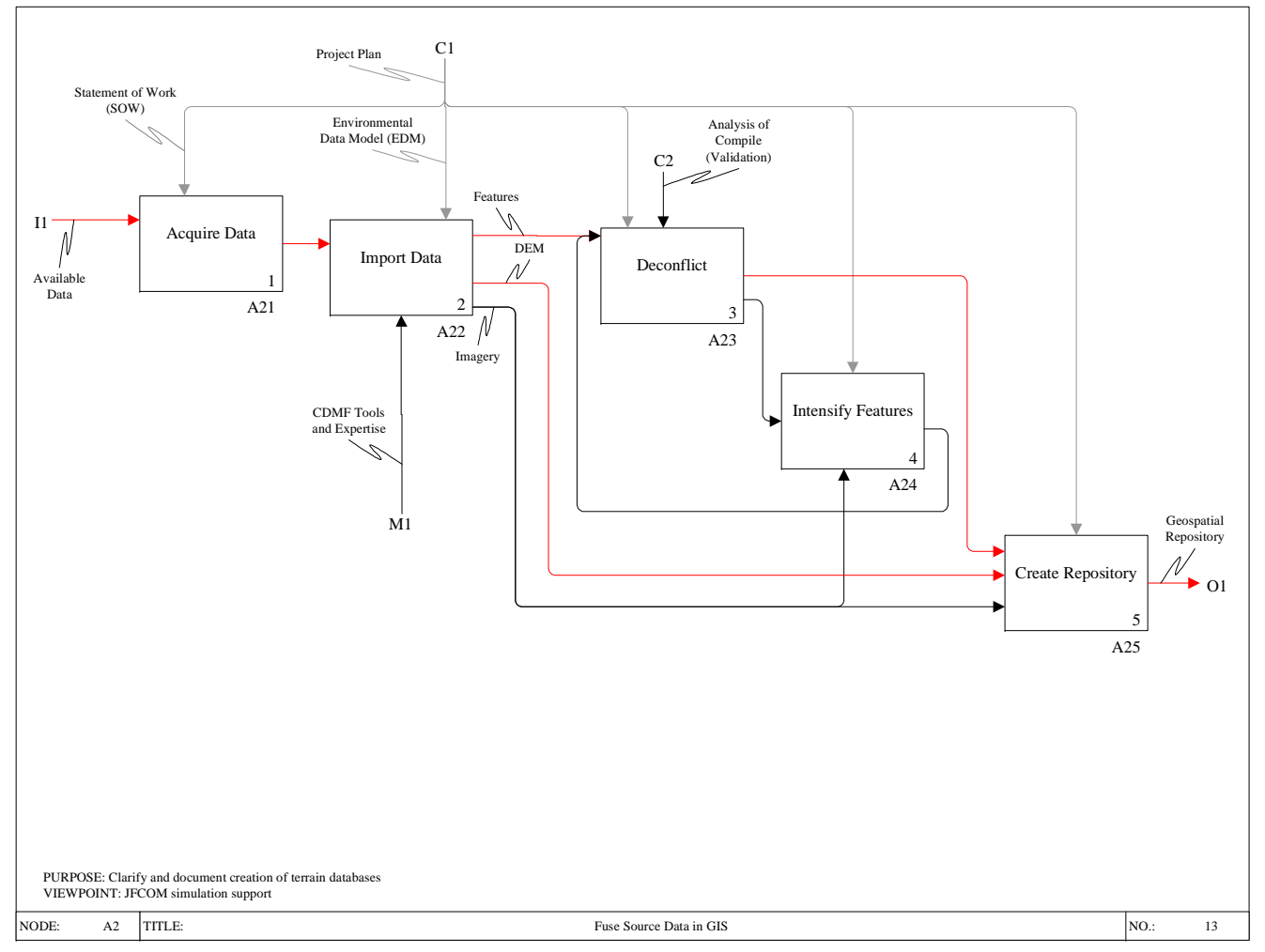
these data.

Relevant aspects of incoming data must be extracted. The data may be filtered to extract relevant extents and content. In the event of poor data quality, additional source data may need to be acquired. 


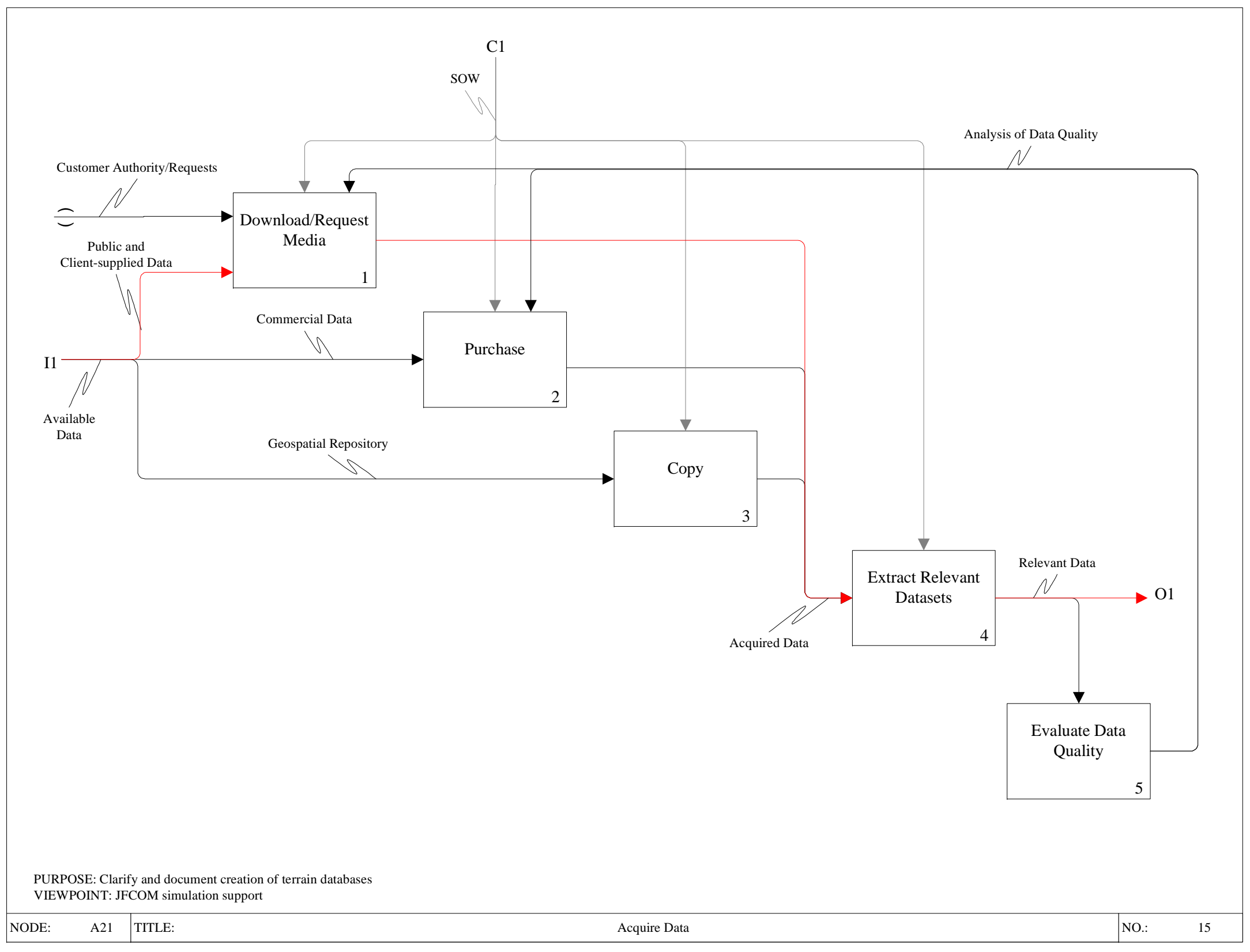




\section{A22 Import Data}

Before conflicts in source data can be addressed, the data must be converted to a common structure - to compare apples to apples.

First, data are imported to native GIS formats and self-conflicting information is resolved when possible. (For example, minute breaks in topology caused by rounding errors or overlapping buildings may need to be resolved.)

Then, we convert all vector data (features) to a common spatial reference frame, usually Universal Transverse Mercator (UTM) projection. This allows integration of sources, but also prepares for the deconfliction and intensification efforts that tend to require storing features in "real world" units, meters.

Mapping information across different data schemas and even ontological perspectives becomes challenging for highly attributed data sets. CDMF and related TEC tools facilitate this mapping to a single EDM.

Tiled imagery and Digital Elevation Models (DEMs) are consolidated into Image Catalogs to ease the use of these data sources.

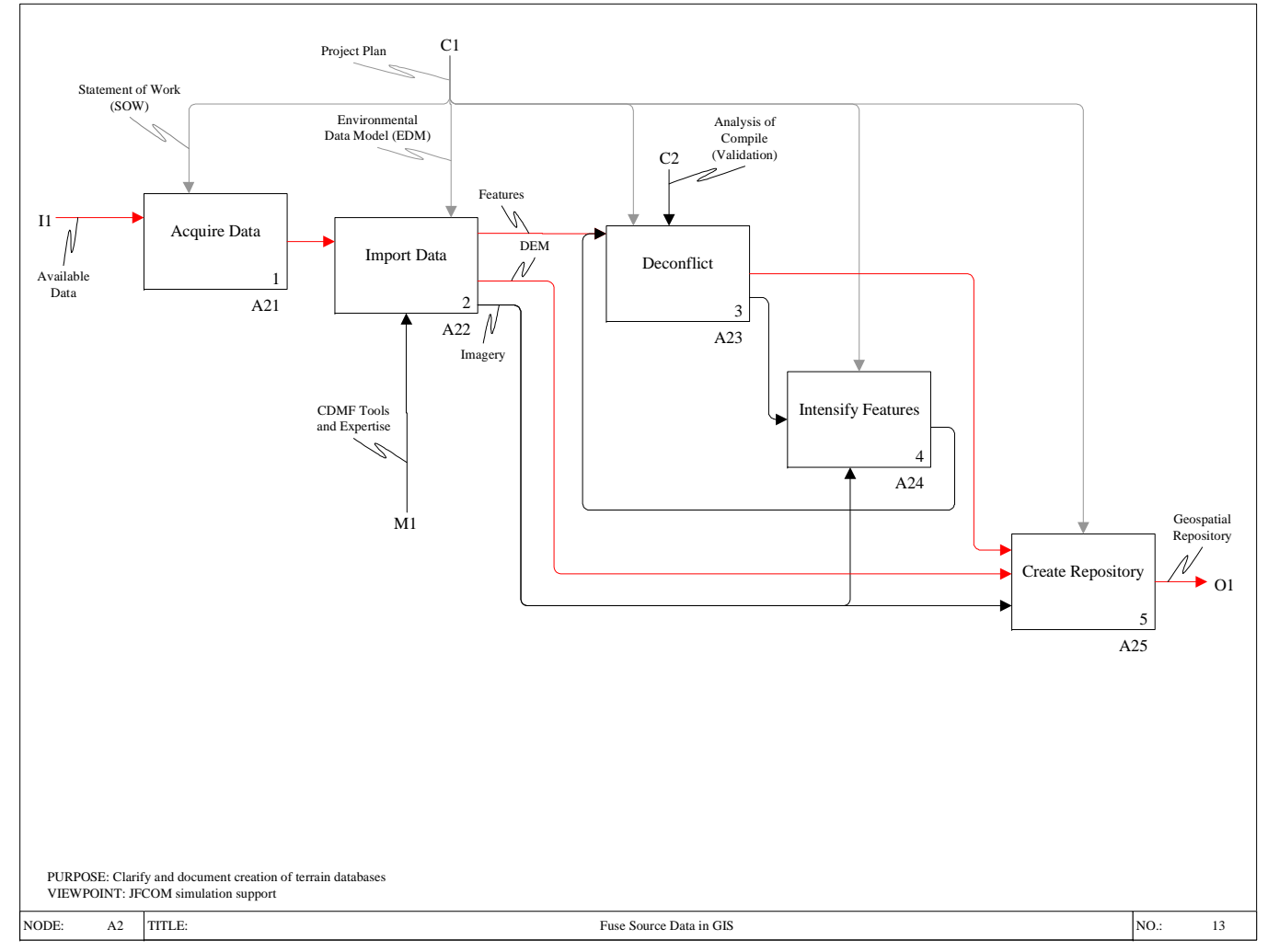




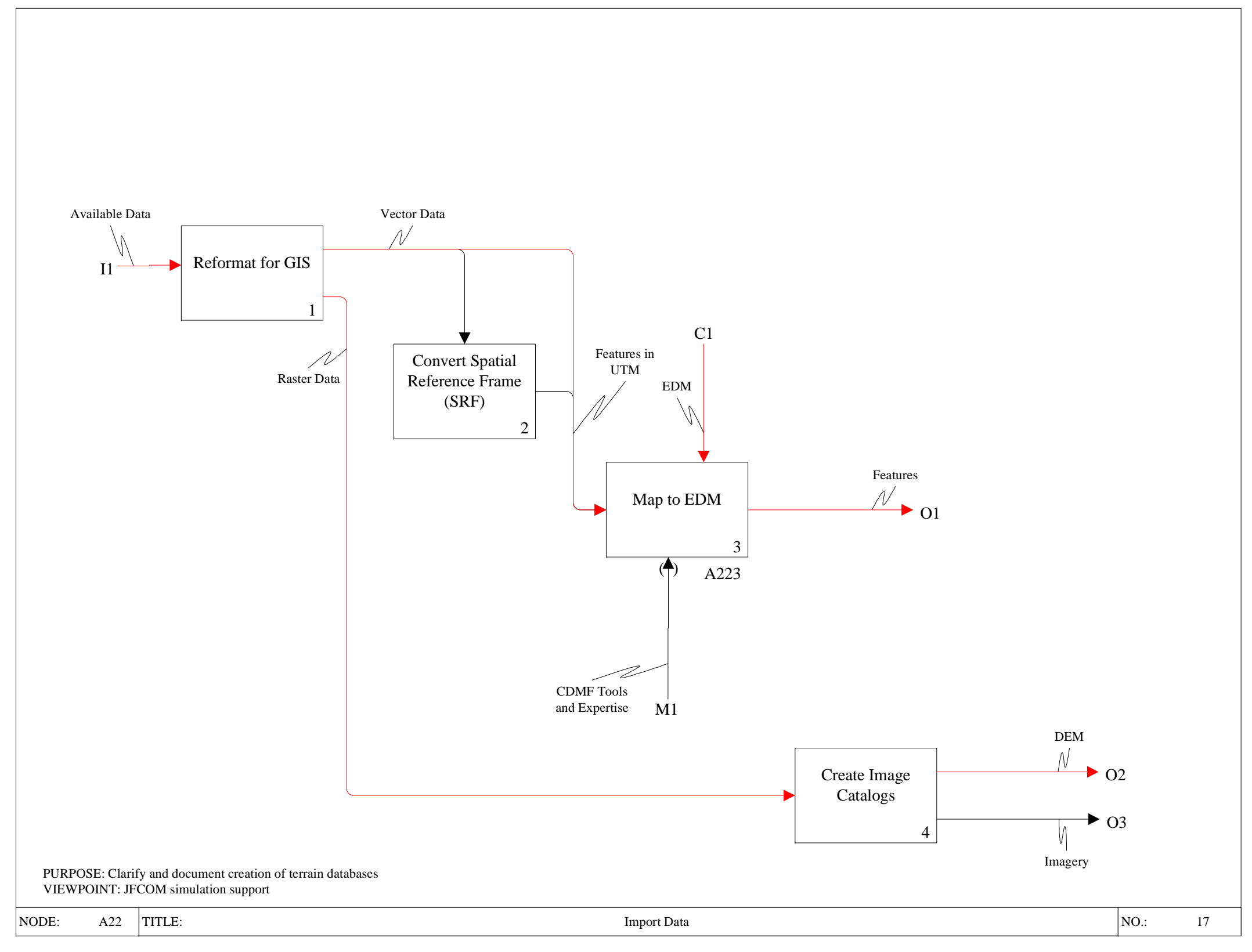


EDMs encapsulate feature lists, feature relationships, associated attributes, and attribute constraints. Translation of concepts across EDMs can be complex.

Lighthouse features in one EDM may need to be converted to Building features with a building function of "lighthouse."

Measurement units may shift between EDMs, or one EDM may use a binned attribute (0-5, 6-10,11-15,..) where another records more precise values.

Trees in one EDM may be represented as points with width attributes but must be translated to areas for another EDM.

All of these issues must be addressed as

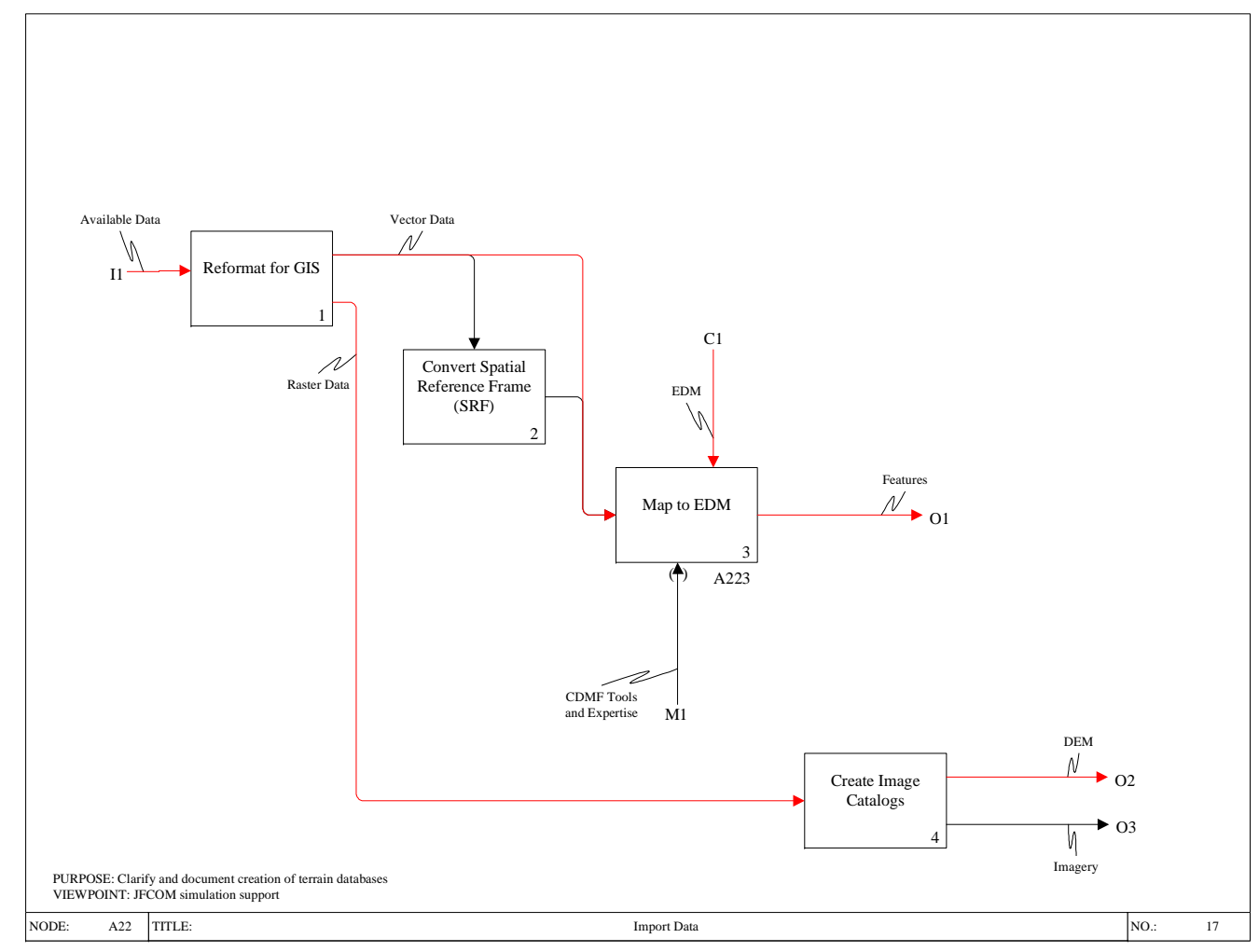

data are translated from source EDMs to the project EDM, which defines the data requirements for a given TDB. 


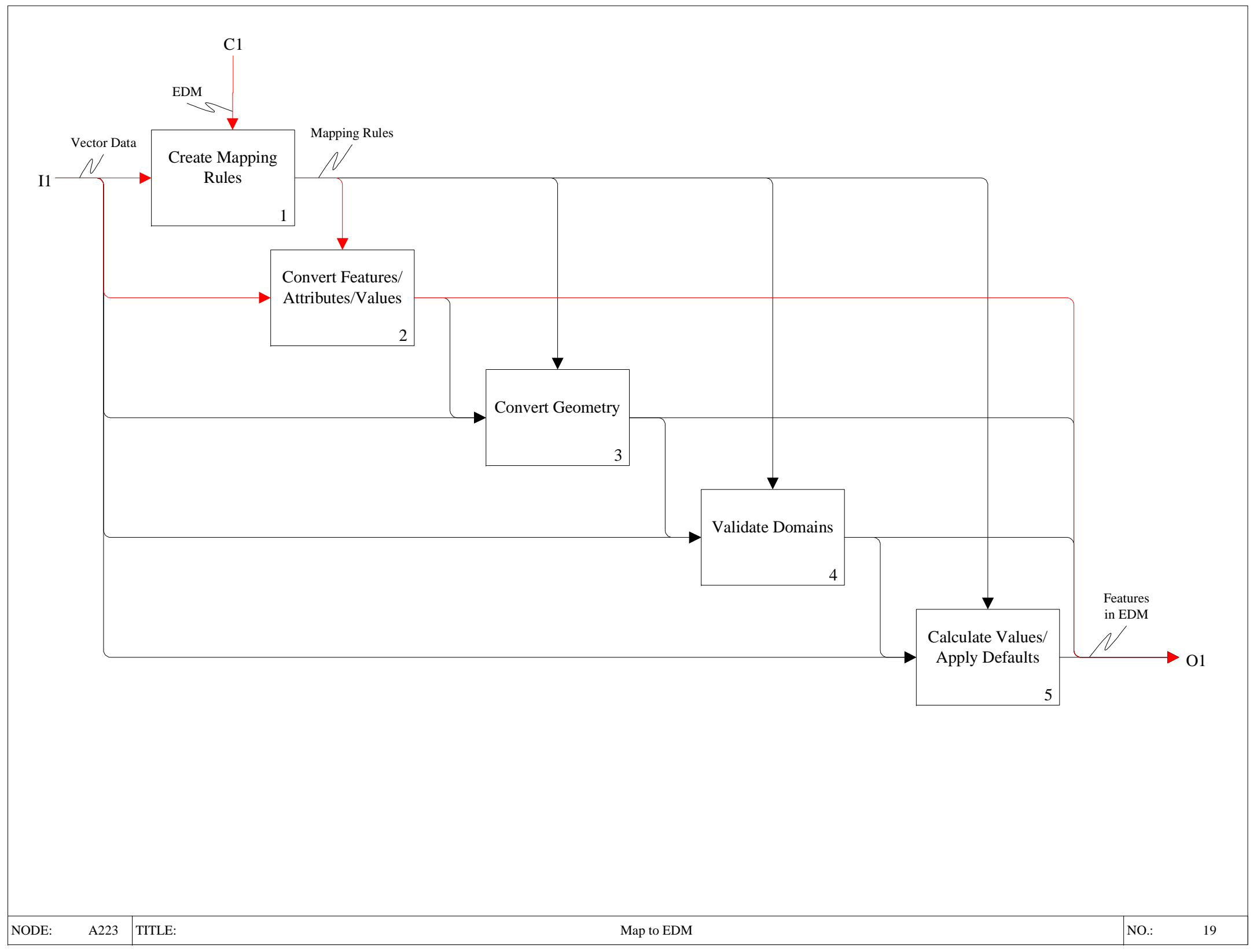




\section{A23 Deconflict}

The integration of multiple data sources, particularly when dealing with varying resolutions, results in conflicts among the data. Buildings may be placed in the middle of the road. Coastal roads may weave in and out of the water. Roads may cross rivers without any associated bridges or fords. Roads from one data source have the best spatial accuracy, but those from another source may contain required attribution.

The four major methods for dealing with these conflicts are:

- Applying ranks to feature types, attribute values, or source information and proclaiming the feature with the highest rank to trump others, which are deleted

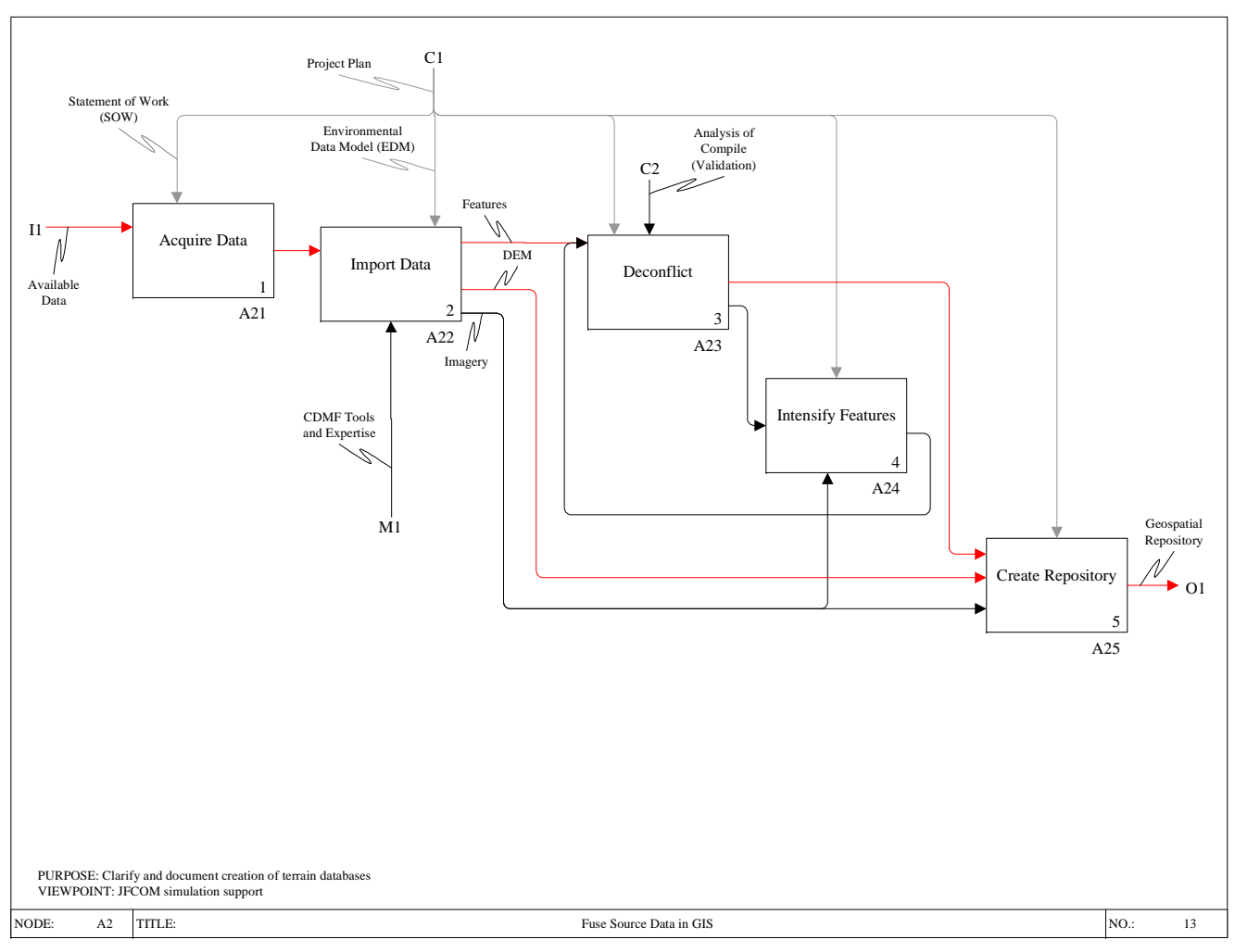
from that area;

- Shifting or rerouting features to avoid conflicts;

- Synthesizing new simulated features (e.g., bridges) to reconcile conflicts; and

- Conflating attributes from one source to features from another source.

While data fusion has been and will remain a difficult technical challenge, in the past much disparate old data was all that was available and conflicts were unavoidable. Today, advances in geo-registration and geospatial data collection are providing higher quality data. Even data collected by different organizations with different techniques with accurate geo-registration has been found to provide almost no conflicts. This improves our ability to develop quality fused datasets. 


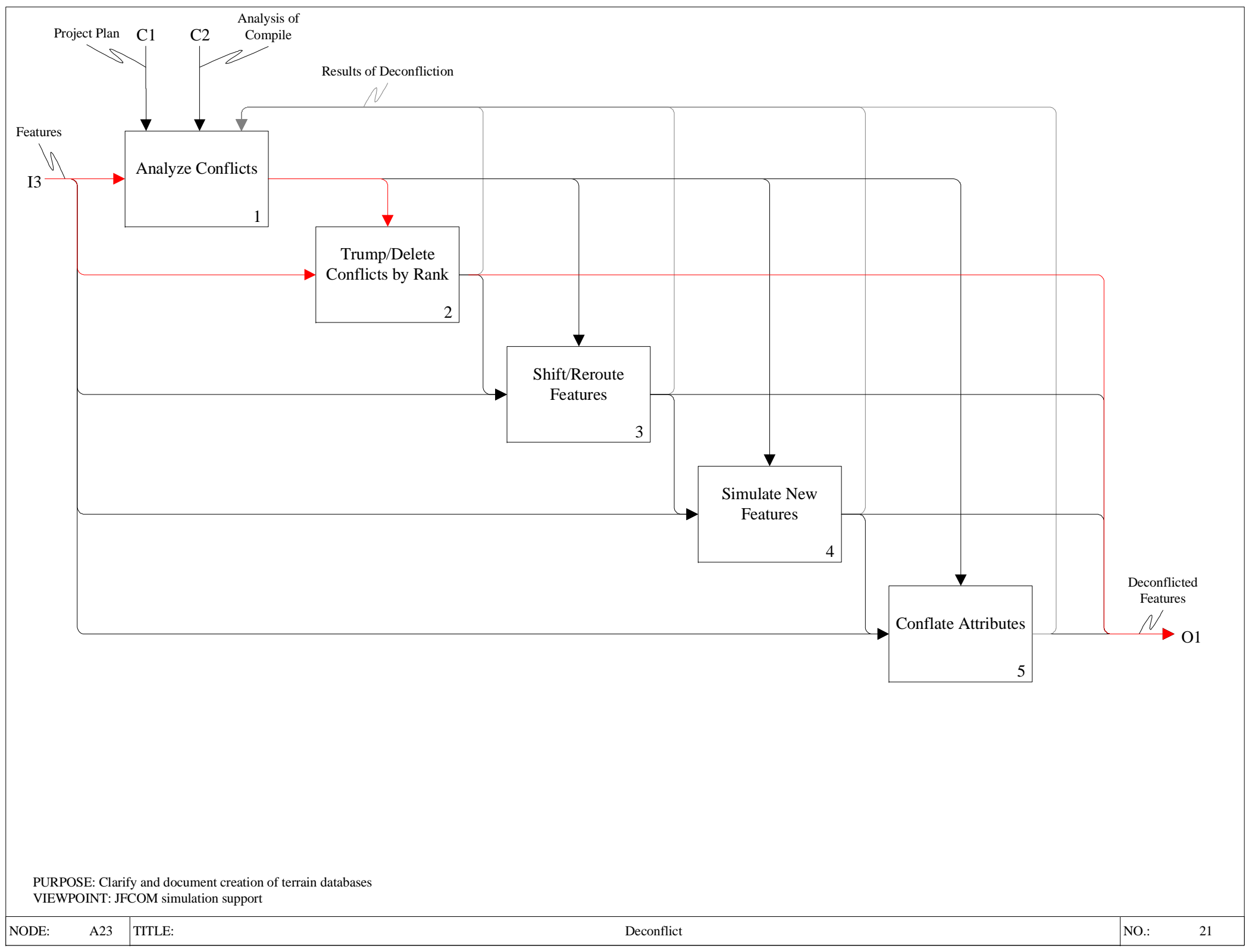


The unique combination of data and requirements for any given TDB project often necessitate the modification of existing features or the creation of new features.

Generally these modifications and additions derive from imagery using "headsup" digitization on computer screens.

New synthetic features may be placed manually or by using automated randomization.

Attributes may be obtained and applied from other sources, derived from imagery, defaulted, or given stochastically applied geotypical values.

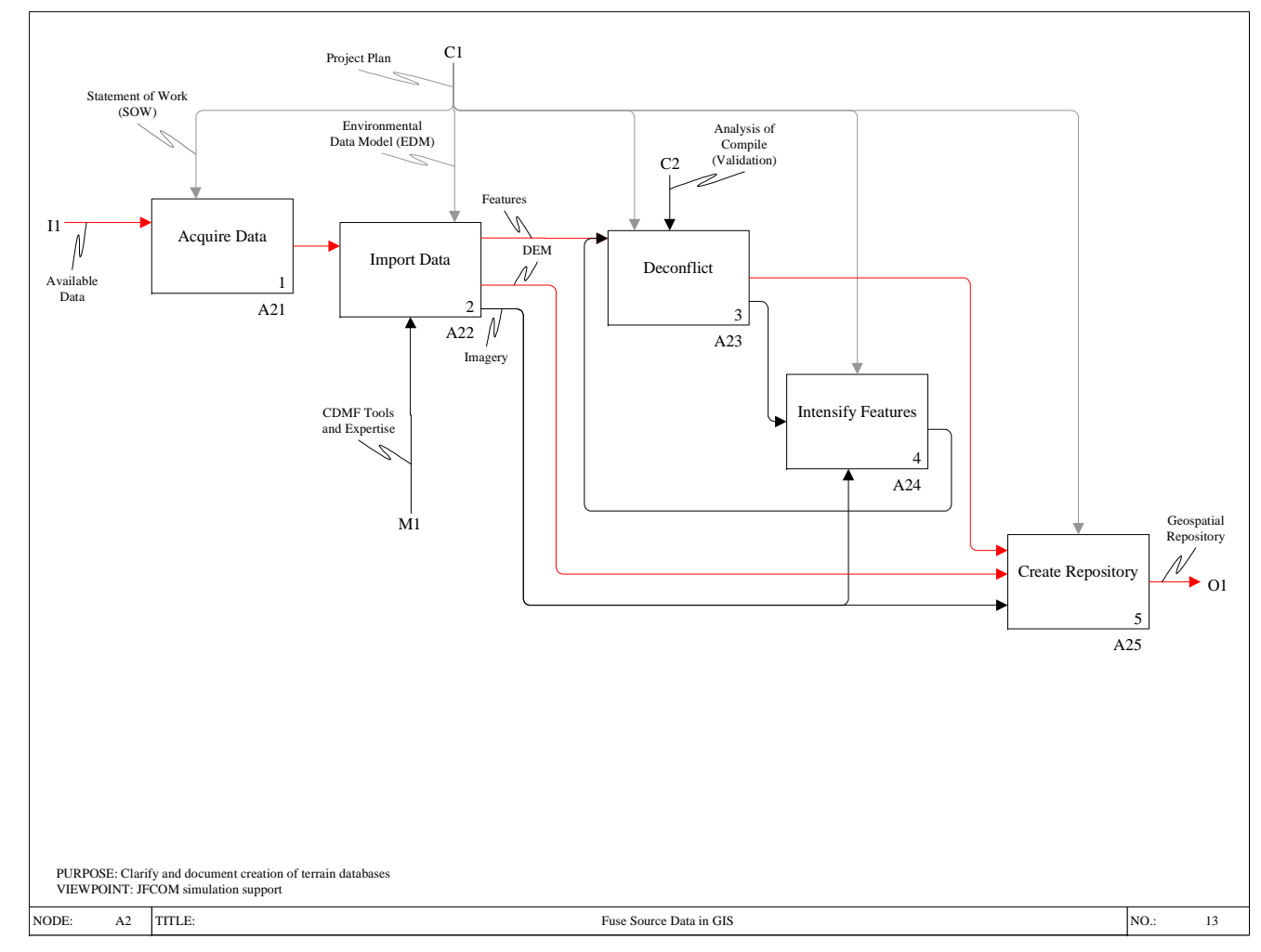

If high fidelity buildings will be generated for a TDB, then Urban Terrain Zones (UTZ) are delineated during intensification.

Features may be given attribution to associate them with 3-dimensional (3D) models for later placement in TDBs. 


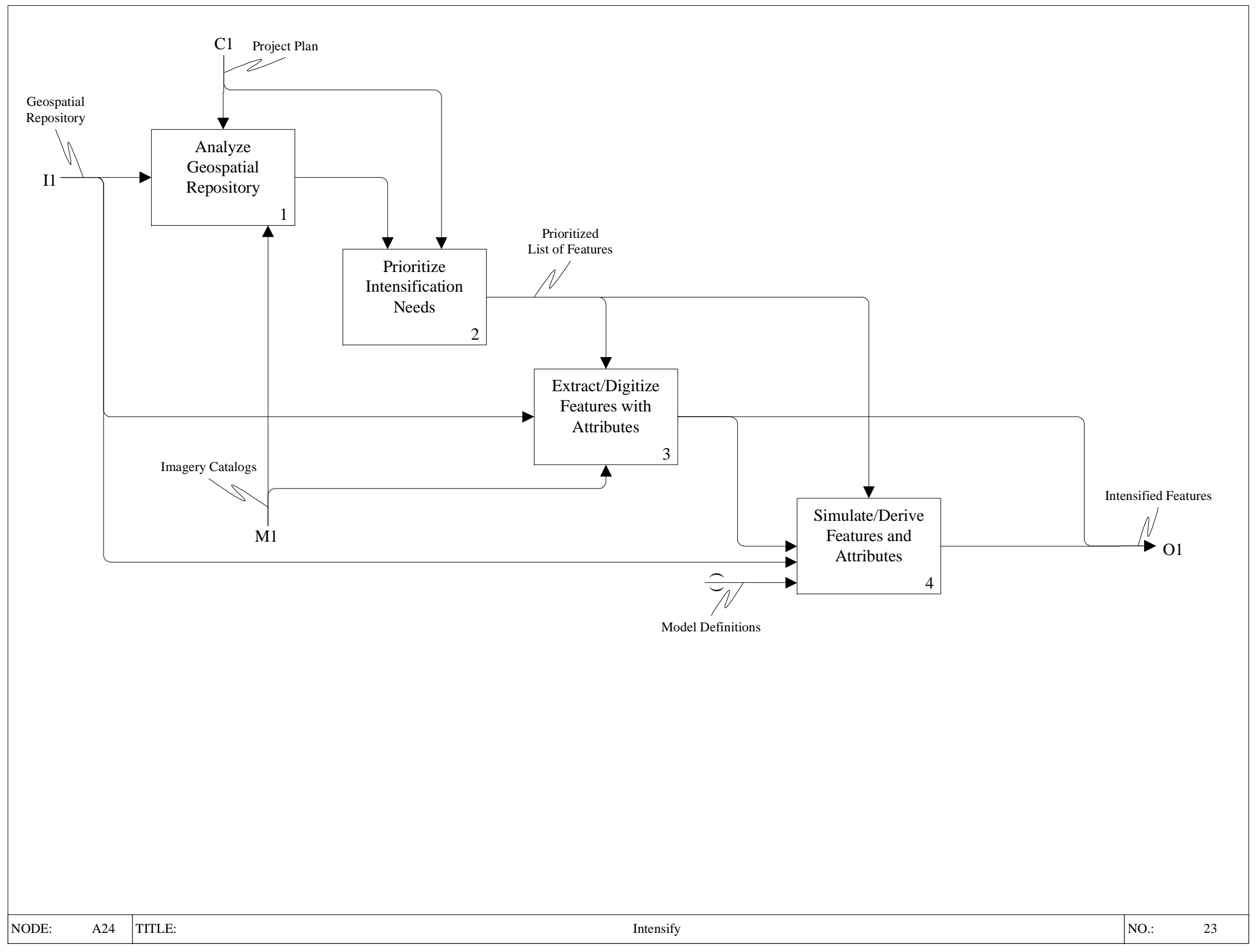




\section{A25 Create Repository}

In preparation for processing of the 3D surface, intensified and deconflicted vector features, DEMs, and imagery are consolidated into a common repository. Enterprise Geodatabase using the Spatial Database Engine (SDE) by ESRI is emerging as a single storage format for features, imagery, and DEMs.

Data are unprojected from UTM to geodetic coordinates to facilitate processing in terrain tools.

In practice, many TDBs contain multiple resolutions. They require high resolution and high fidelity within one or more areas of interest (AOI), but use lower resolution and fidelity in a larger play box. The integration of vector features across the AOI/play box boundary is accomplished in Edge Match (A251). The integration of DEMs across resolutions occurs in function A252.

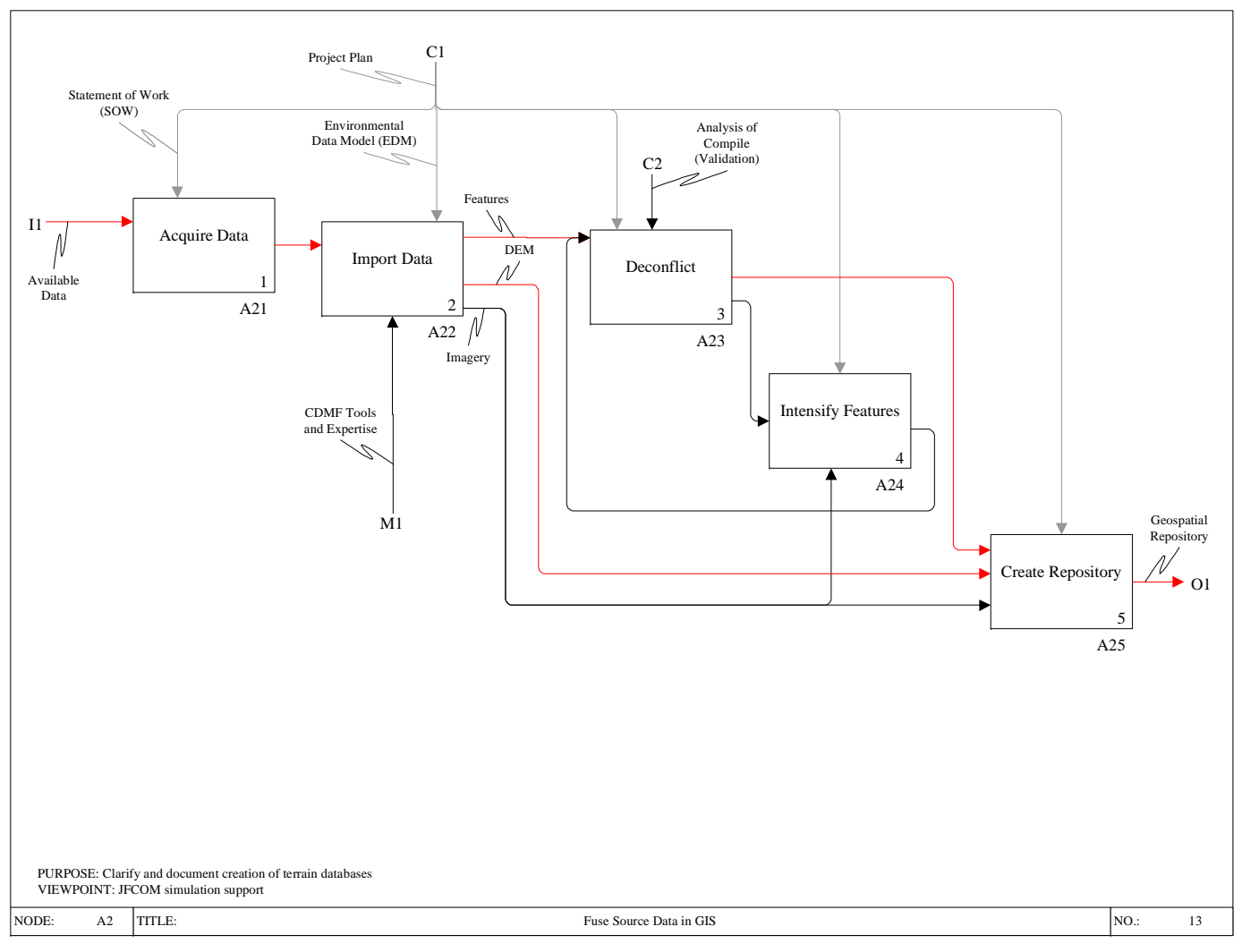




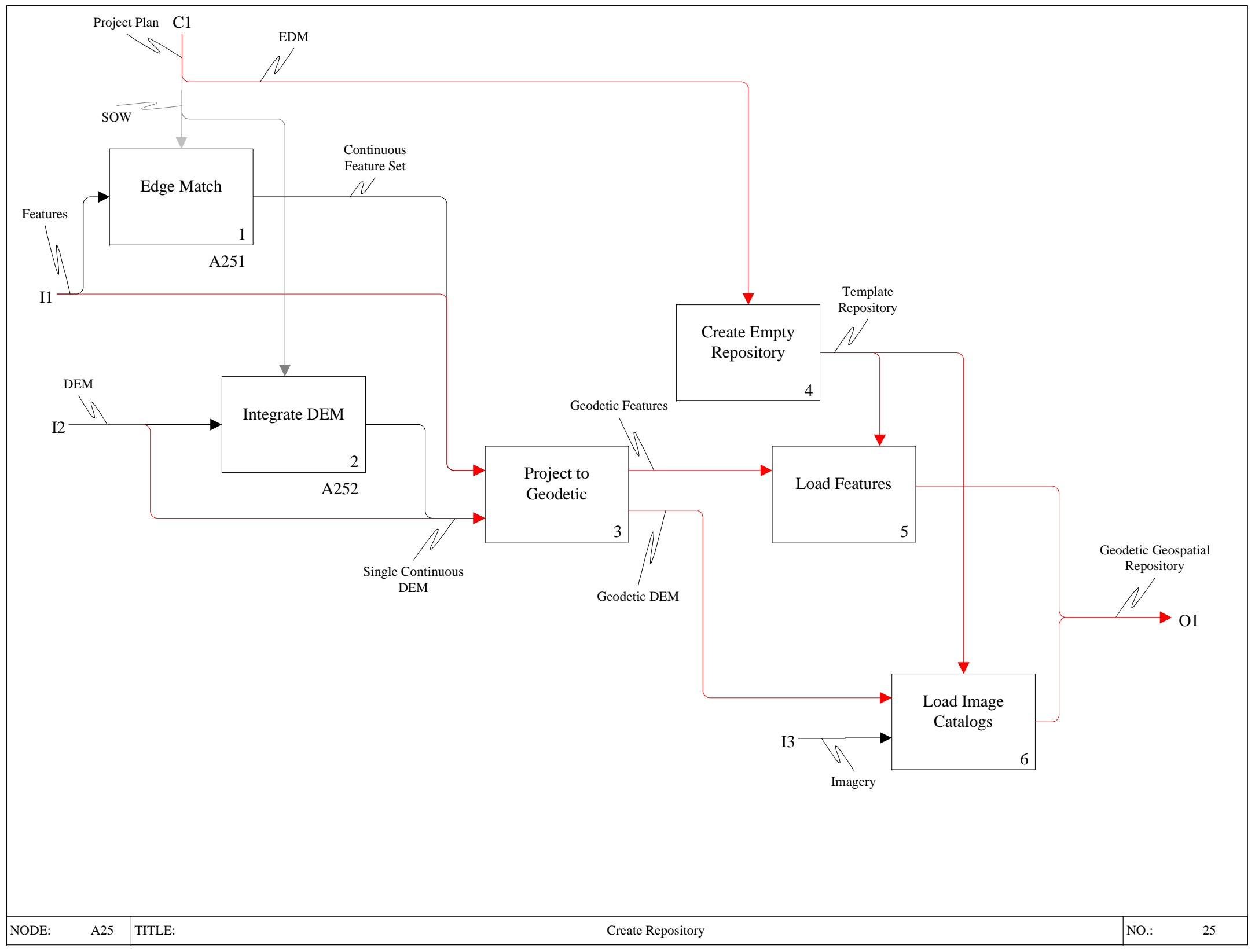


The Edge Match function clips data according to fidelity for both the AOI and the remaining area that falls within the play box, but outside of any AOI.

For example, a play box might hold data appropriate for a notional map scale of 1:100,000 and an AOI might include data for a scale of 1:5,000.

After clipping, linear and areal features become disjoint. Linear features, such as roads, must be connected to maintain the topology required by simulations. Small breaks in the road network can result in illogical vehicular behavior in a simulation.

Breaks in area features across the

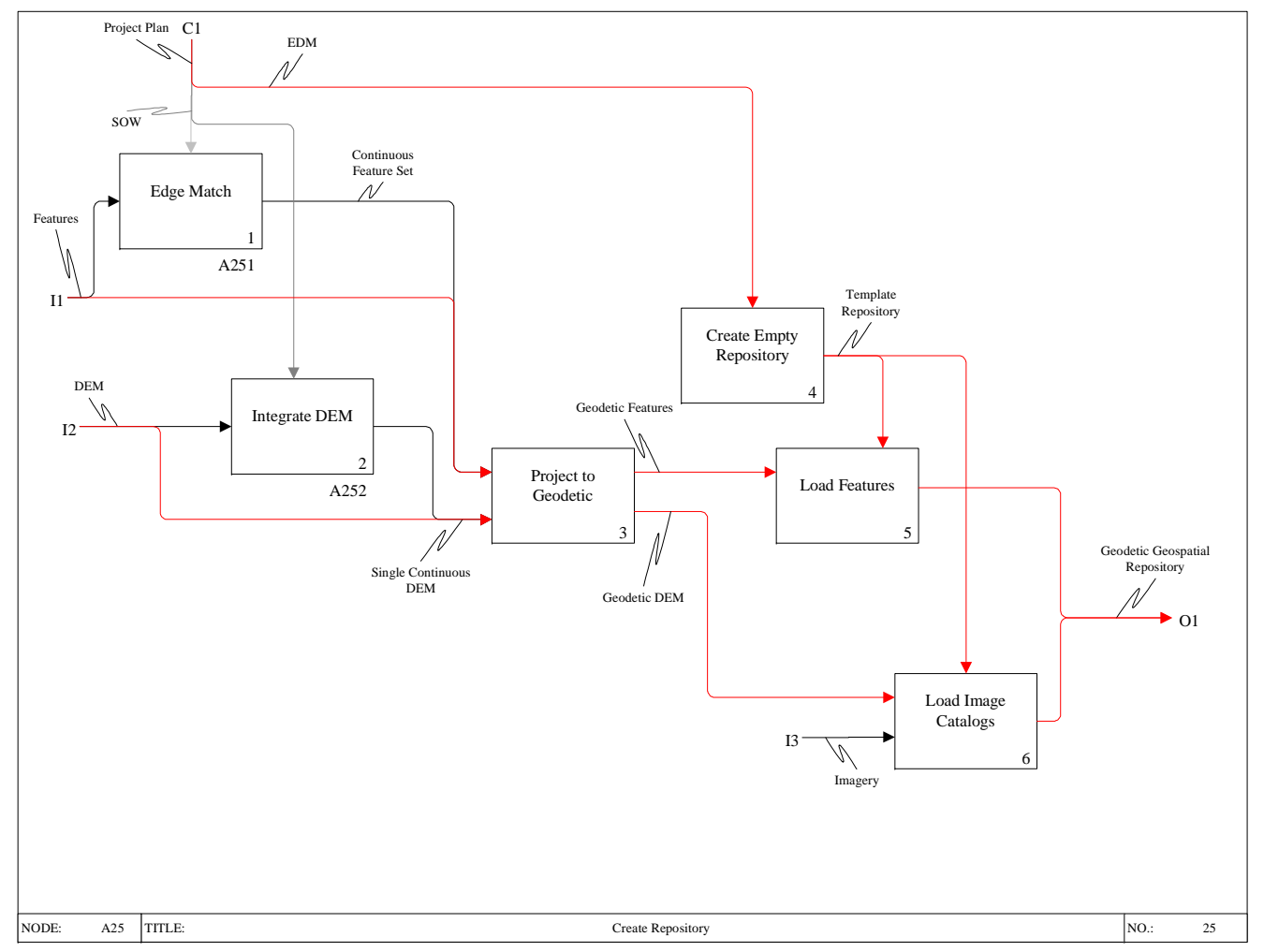

AOI/ play box boundary must be handled as well. GIS technicians may need to resolve the problem where high resolution shore for a lake does not match up with the low resolution lake area or if a pond displayed in only the AOI abruptly ends in a rigidly straight line. 


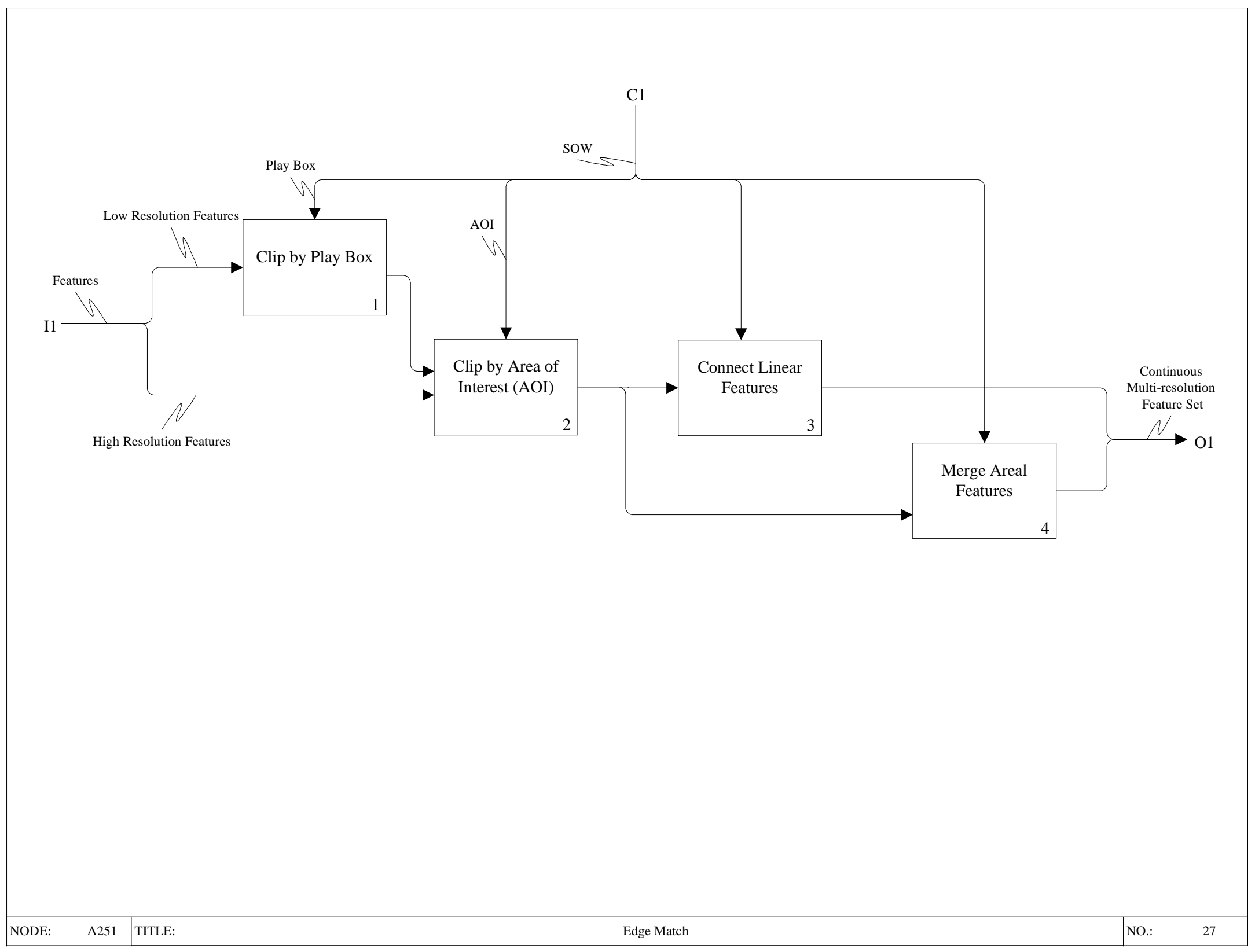


Integration of the DEM requires clipping data sources similarly to that accomplished for features in Edge Match.

Filtering of the DEM may be performed at this time to remove artifacts of data collection, such as inappropriate "cornrows" in the elevations.

Seaming a DEM allows for a gradual shift in elevation among source DEMs and prevent cliffs being created at the AOI/play box boundary.

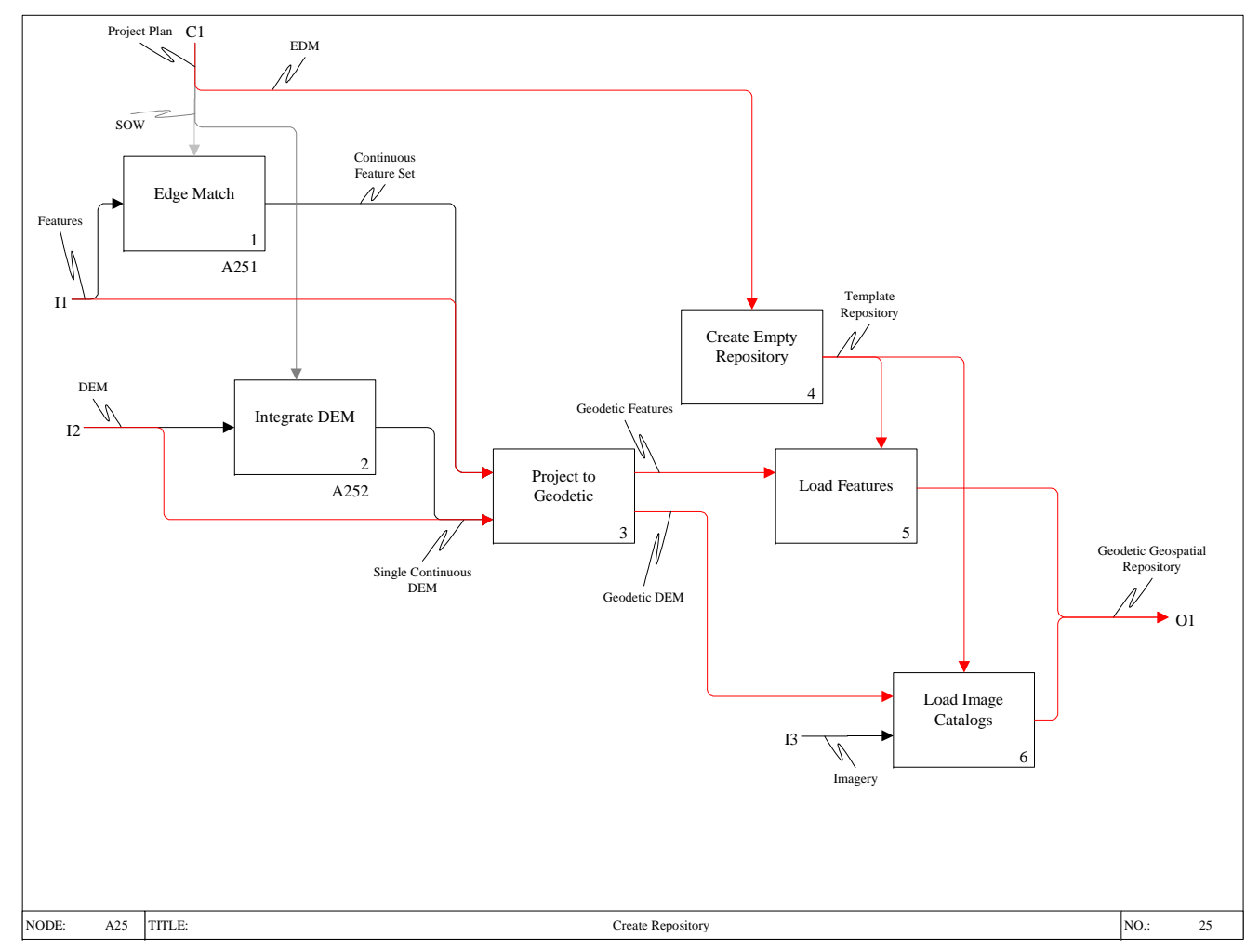




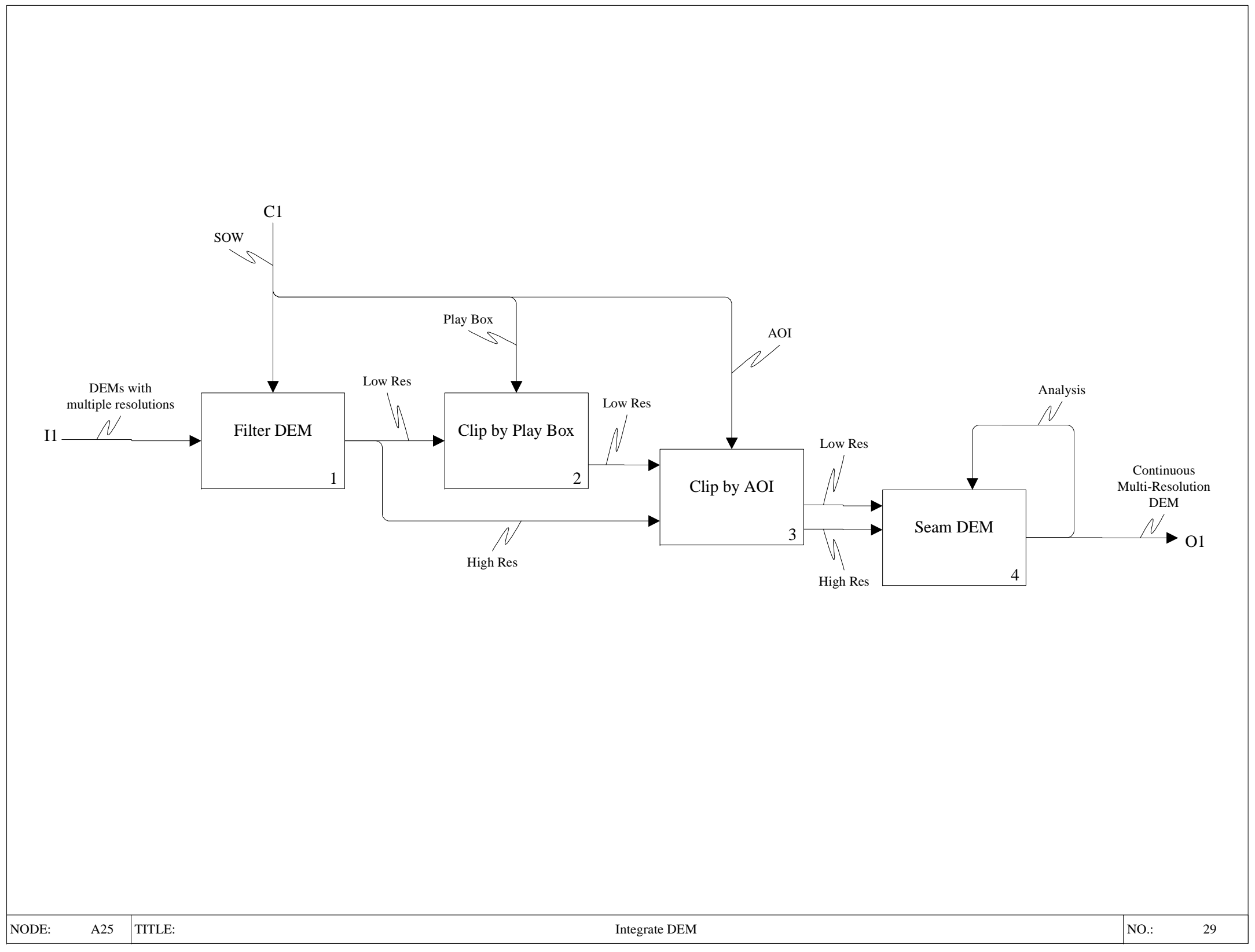




\section{A3 Generate High Fidelity Buildings in ABGS}

TEC has created and continues to improve its Automated Building Generation System (ABGS). ABGS is a set of tools that logically and geotypically derive attribute values for building footprints and create high fidelity 3D models of buildings based on the footprints and attributes.

ABGS tools infer building height, function, and other attributes based on a building footprint's area, spatial context, and a configurable "probability curve." UTZs describe a combination of characteristics for a set of buildings including spacing (dense to sparse), height, and commonly occurring building functions.

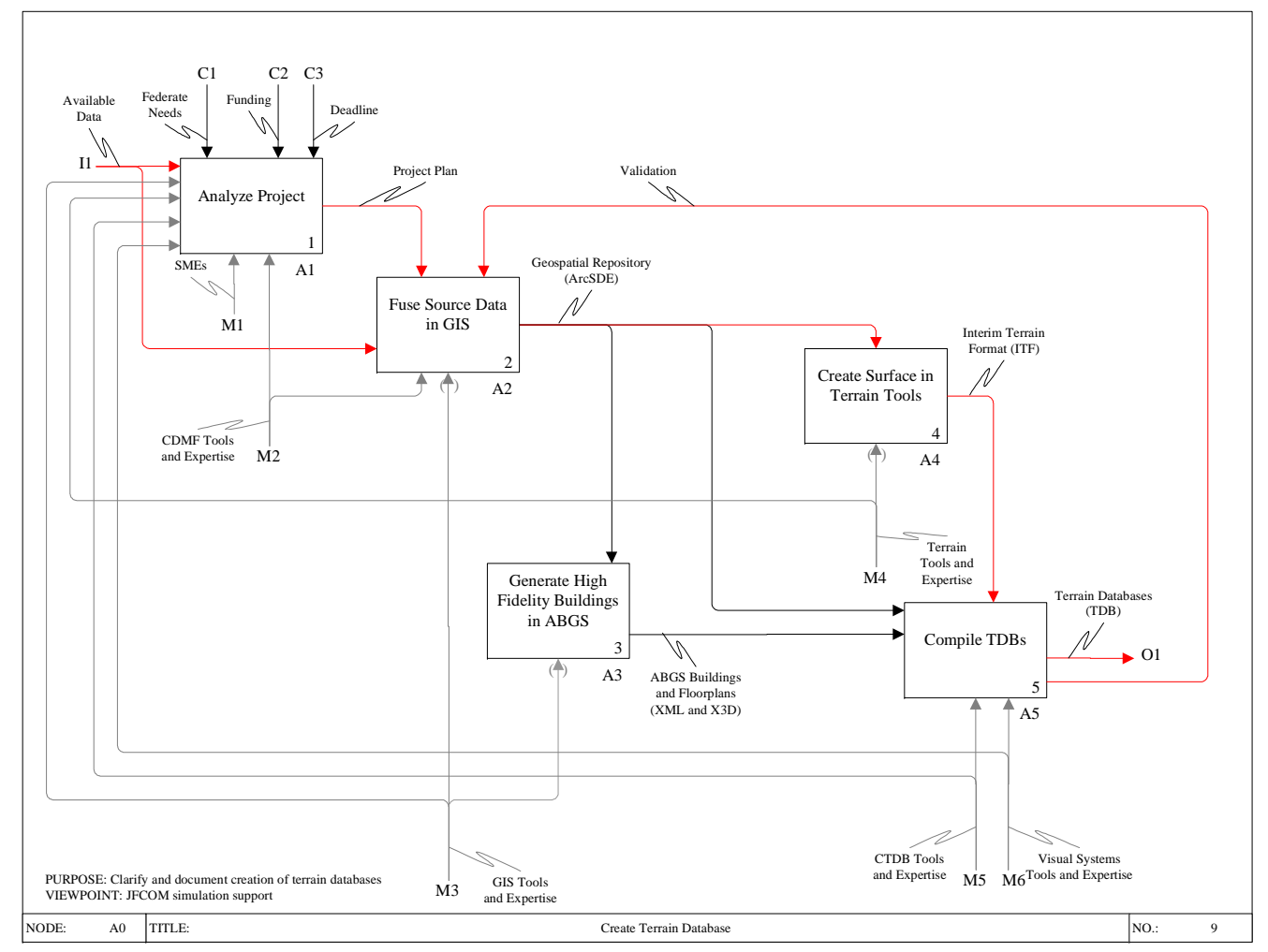

Road proximity is used to define the primary entrance to a building.

Floor plans and physical models may include multiple stories, shaped roofs, interior and exterior doors, interior and exterior walls, windows, stairways, and elevator shafts. These elements vary in quantity, size, and texture depending upon the building function and other building attributes. 


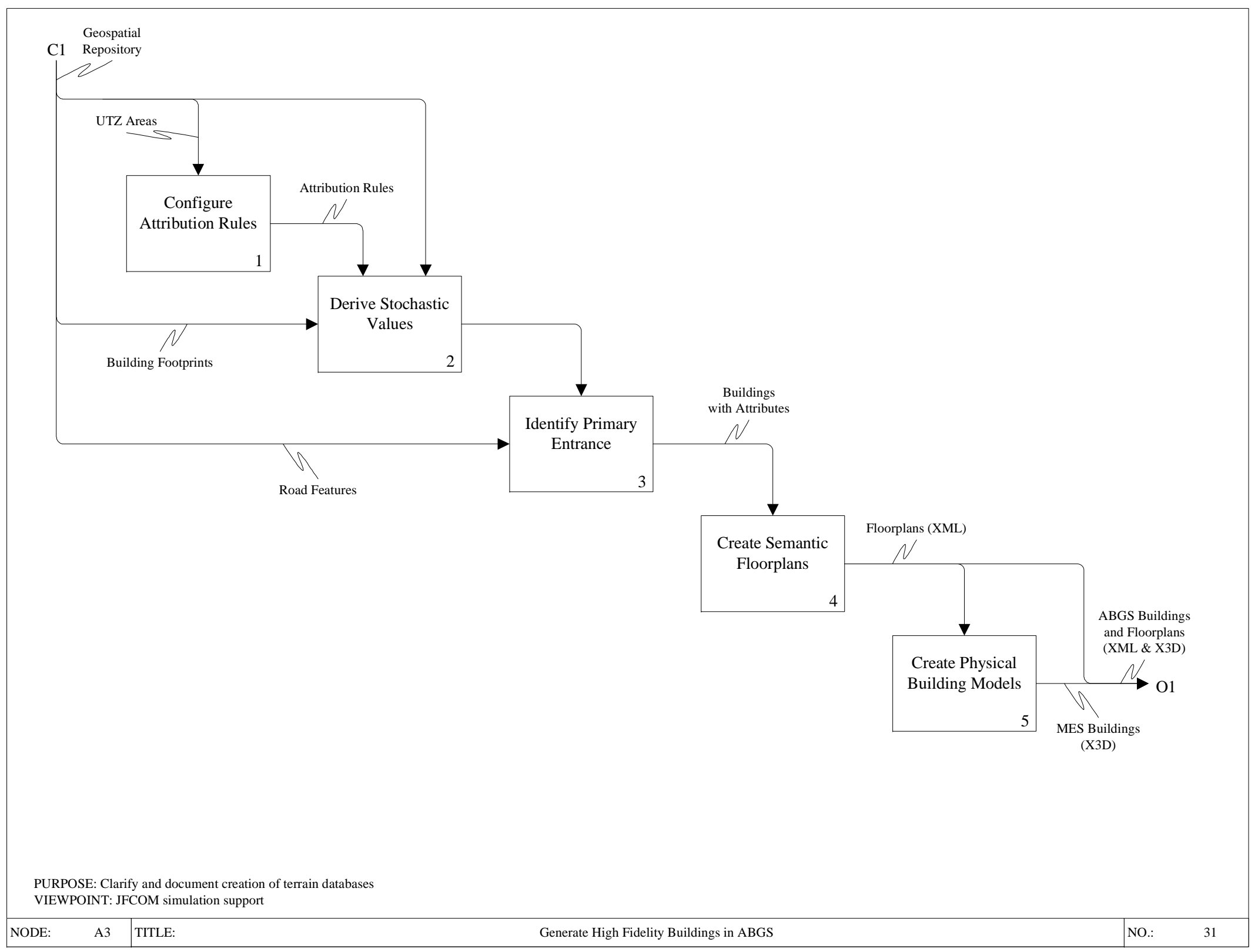




\section{A4 Create Surface in Terrain Tools}

Although Geographic Information Systems contain the best functionality for managing and editing 2-dimensional (2D) vector features and for certain processing of DEMs, terrain tools ease processing of 3D data. All the functions within A4 depend upon the use of terrain tools, such as TerraTools by TerraSim.

The TEC process creates an Interim Terrain Format (ITF), which contains partitioned 2D and 3D data, textures, and models. ITF is consumable by TEC compilers.

The process of creating a surface is broken into six primary steps: (1) generate cells, (2) seam the DEM, (3) impress features, (4) build a triangulated irregular network (TIN), (5) convert to the target spatial reference frame, (6) generate patches within the cell(s). A41 and A43 are

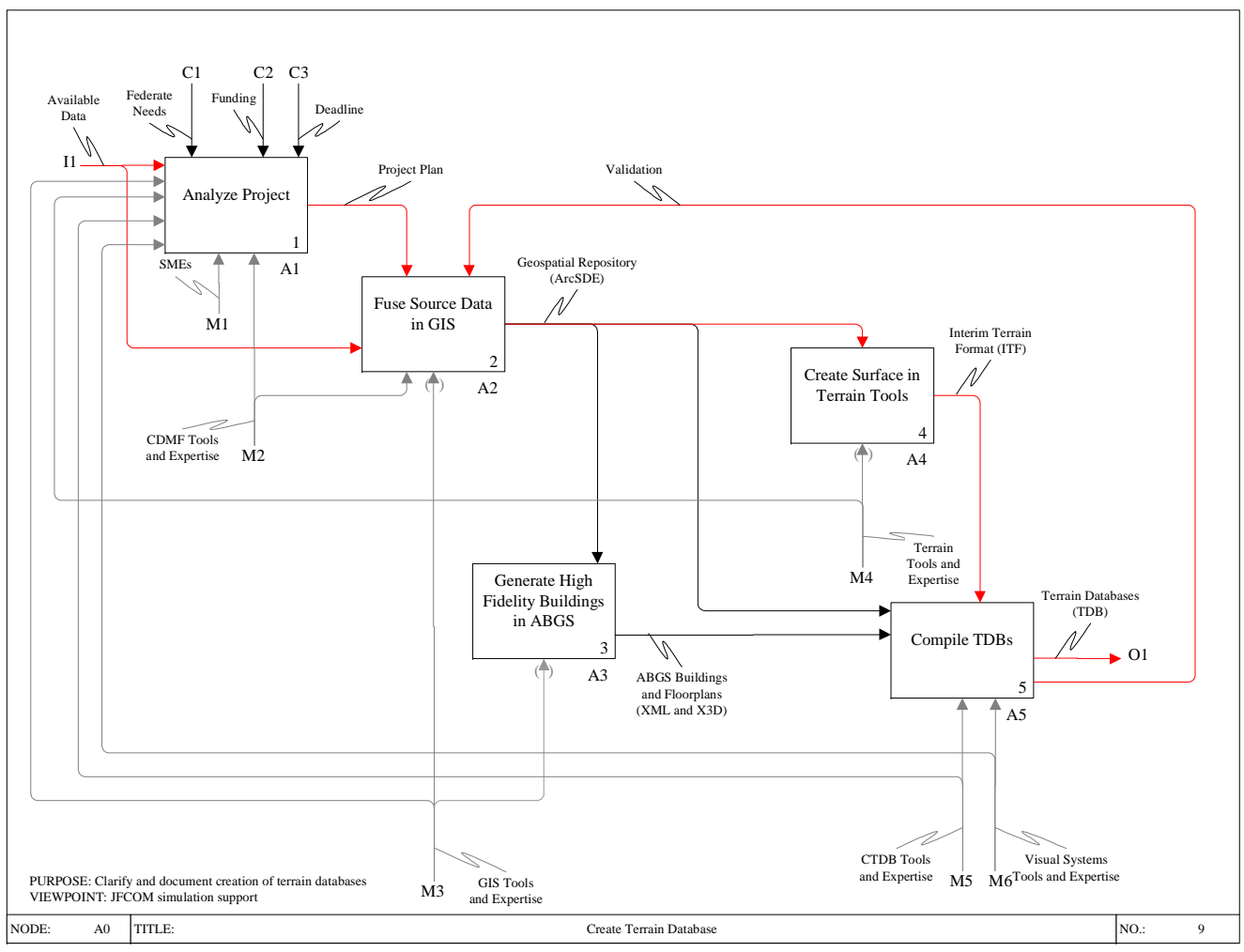
detailed in subsequent diagrams.

Seaming of the DEM may either occur here within the terrain tools or by using GIS in A252. The method selected depends upon the comparative maturity of competing functionality within the two tool sets.

TIN building is an iterative process and must be performed using parameters appropriate for the desired quality/ density of the terrain surface. 
Proper processing within terrain tools often relies on a geodetic spatial reference frame. After building the TIN surface, data are converted to the target projection. TEC generally converts to the tangent plane projections using the GeoTile Reference System for areas encompassing more than single cell. Most TDBs generated by TEC have a worldwide extent. For custom projects, UTM may be used (with no conversion); however, this limits the scope of the TDB.

Patches integrate all the data necessary for ITF and break cells into manageable chunks of data. 


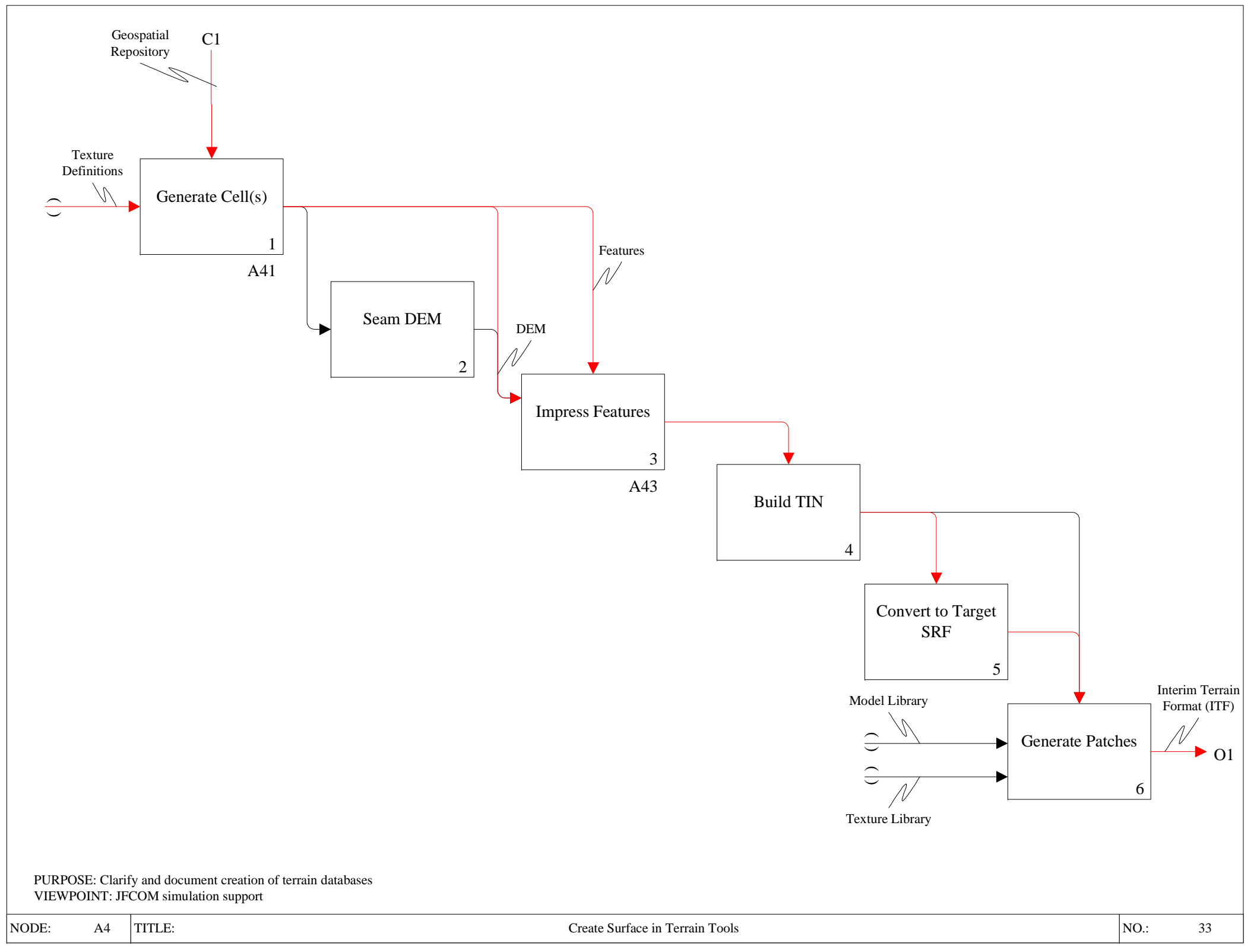




\section{A41 Generate Cell(s)}

Source data is divided into one-degree-byone-degree cells to limit the scope, data sizes and processing time for subsequent terrain surface manipulation and eventual simulation operations.

Features may be derived within terrain tools. For example, bridges may be inferred at the intersections of roads and impassable linear water. Note: this is a competing functionality to that available in GIS tools and performed during deconfliction (A23). In projects for which such derivation is necessary, the method selected depends upon the relative maturity of functionality between the software products.

Attribute values such as the incline of a road may be derived during the process of cell generation.

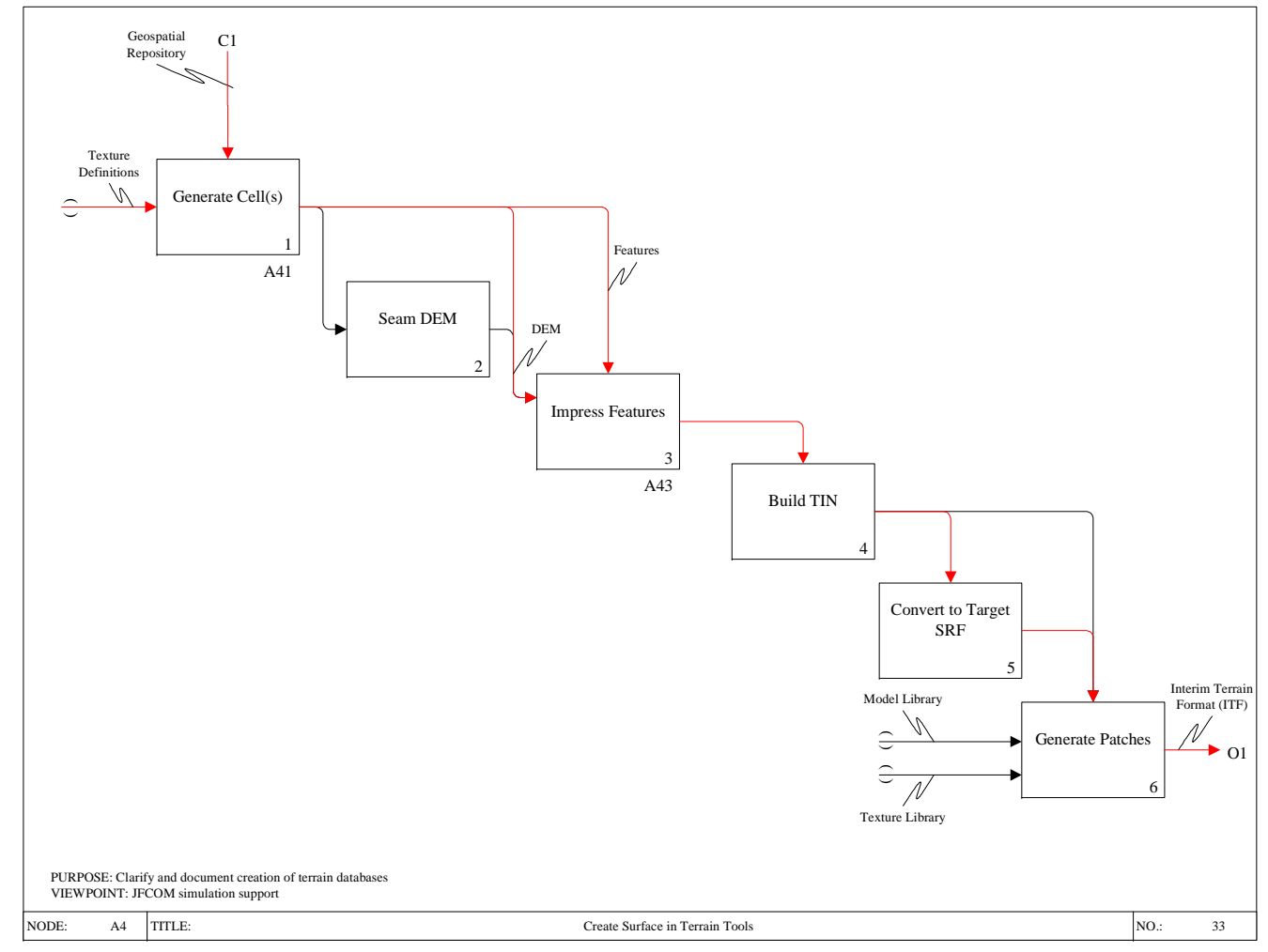

Features are assigned attribute values for texture. Texture is a critical element of visualization and it is highly regionalized. Not all the textures for San Antonio would be appropriate for use in New York City.

The creation of feature indices within cells permits a limited size for index fields and enables full specification of any feature by a combination of cell identifier and feature index. 


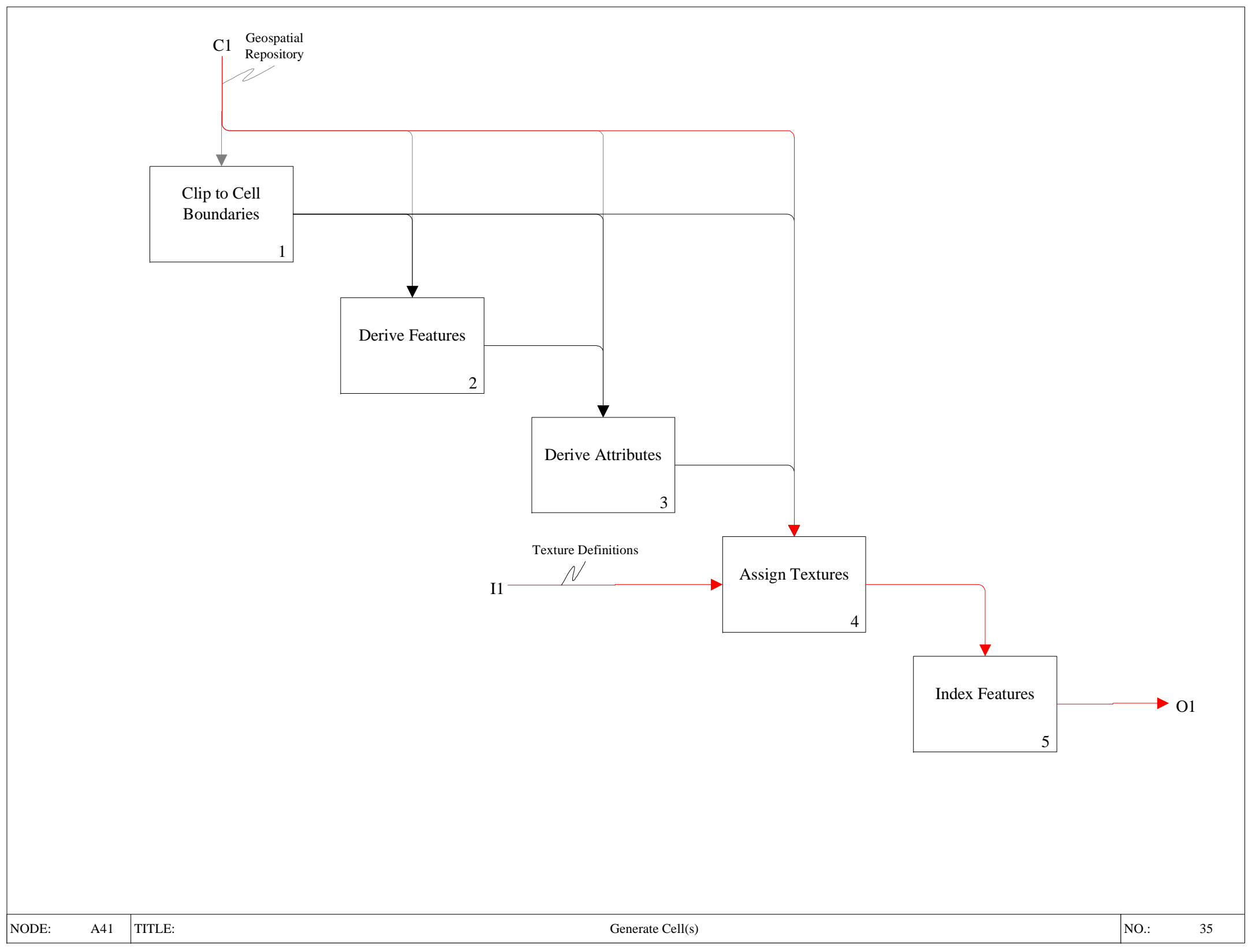




\section{A43 Impress Features}

Impressing features into the terrain is a key function of terrain tools.

To avoid one of the most common conflicts lack of correlation of elevation and coastline - TEC "zeroes" elevation of the ocean along coastlines. This may require raising DEM elevations within a landmass and lowering areas beyond the coast.

Many features are best stored as 2D lines to maintain topology (connectivity): roads, railroads, rivers, and more. The expansion of linear features is an initial step for creating $3 \mathrm{D}$ features from the $2 \mathrm{D}$ lines.

Many types of adjustment to surface elevations are possible. Lakes and expanded

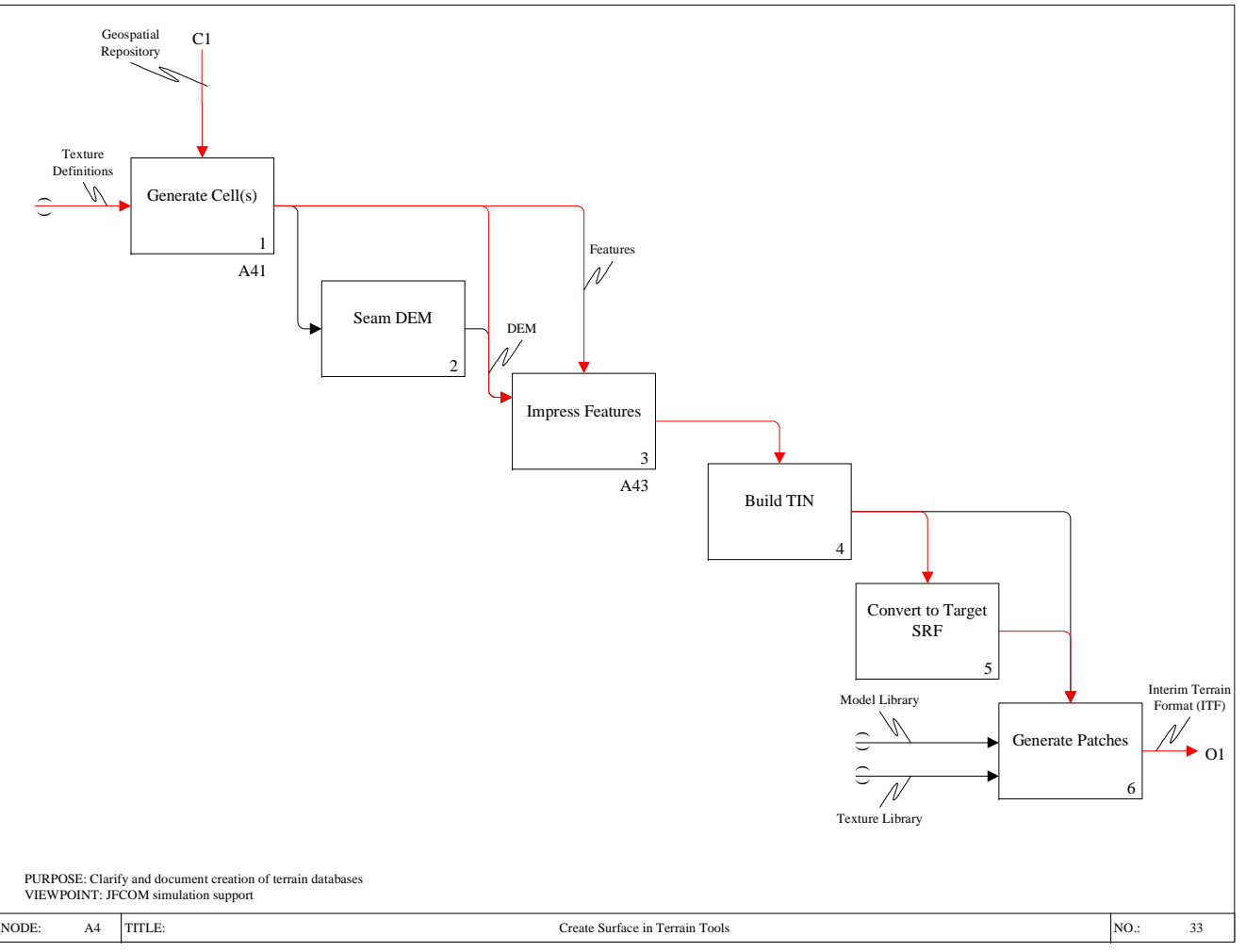
roads/railroads may be used to flatten the elevation surface. Embankment and bluff features may be used to increase elevations. Ditches may be pressed into the surface. The selection of which features to impress is strongly dependent upon the needs identified for a particular TDB. 


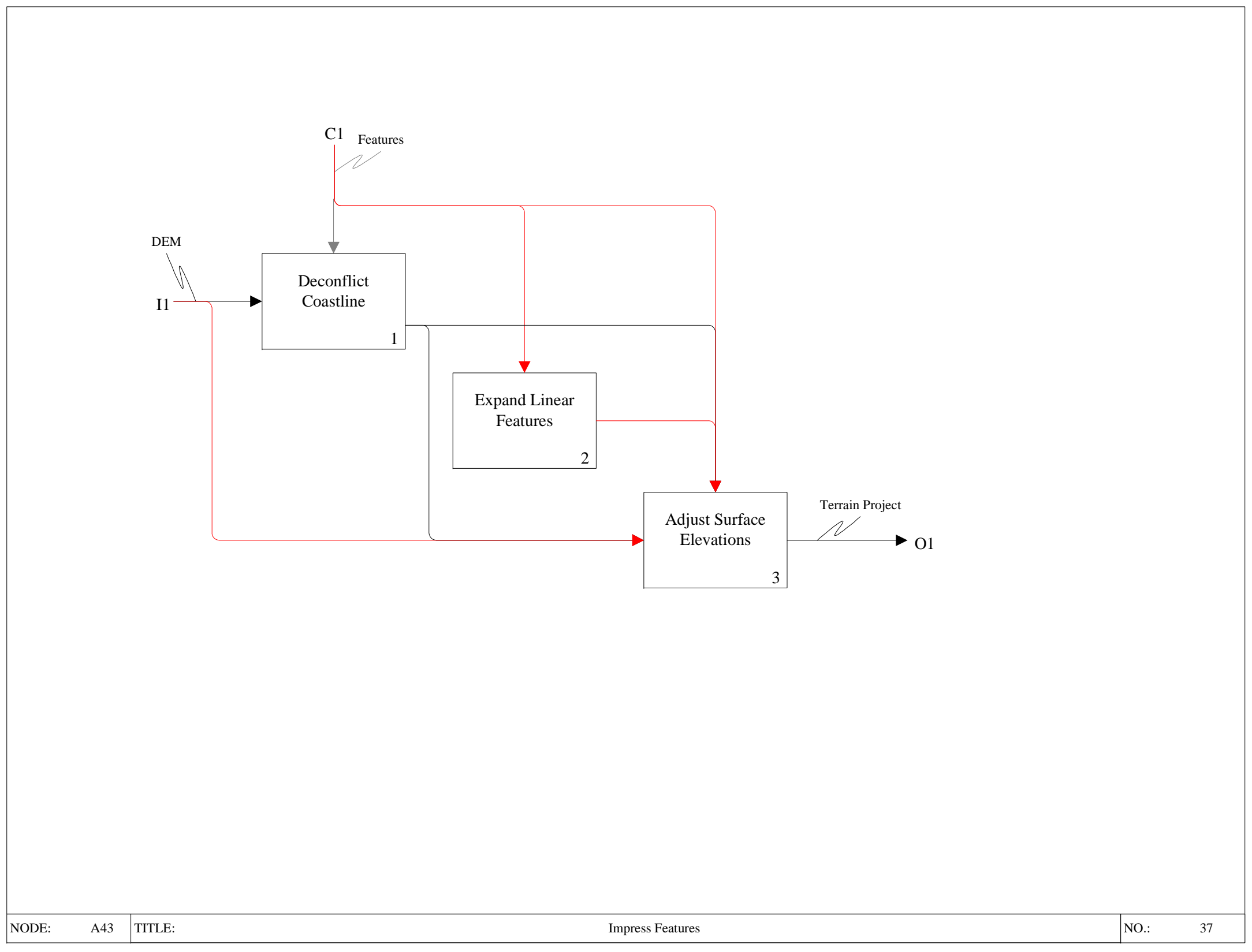




\section{A5 Compile TDBs}

Compiling TDBs has become a highly automated function at TEC. Compilers create TDBs specific to formats readable by simulation federates. The compilation of multiple formats from common inputs guarantees a greater level of correlation among outputs than separately derived TDBs. The common code history for the compilers at TEC further increases correlation among outputs.

The CTDB compiler creates Compact Terrain Databases in Format 8. J oint Semi-

Automated Forces (J SAF) reads and operates upon CTDB. Multicell and Dismount Command and Control (M\&D C2) uses CTDB 8 for Future Combat Systems (FCS). Both systems use CTDB for experimentation.

The visual database compiler creates a fully

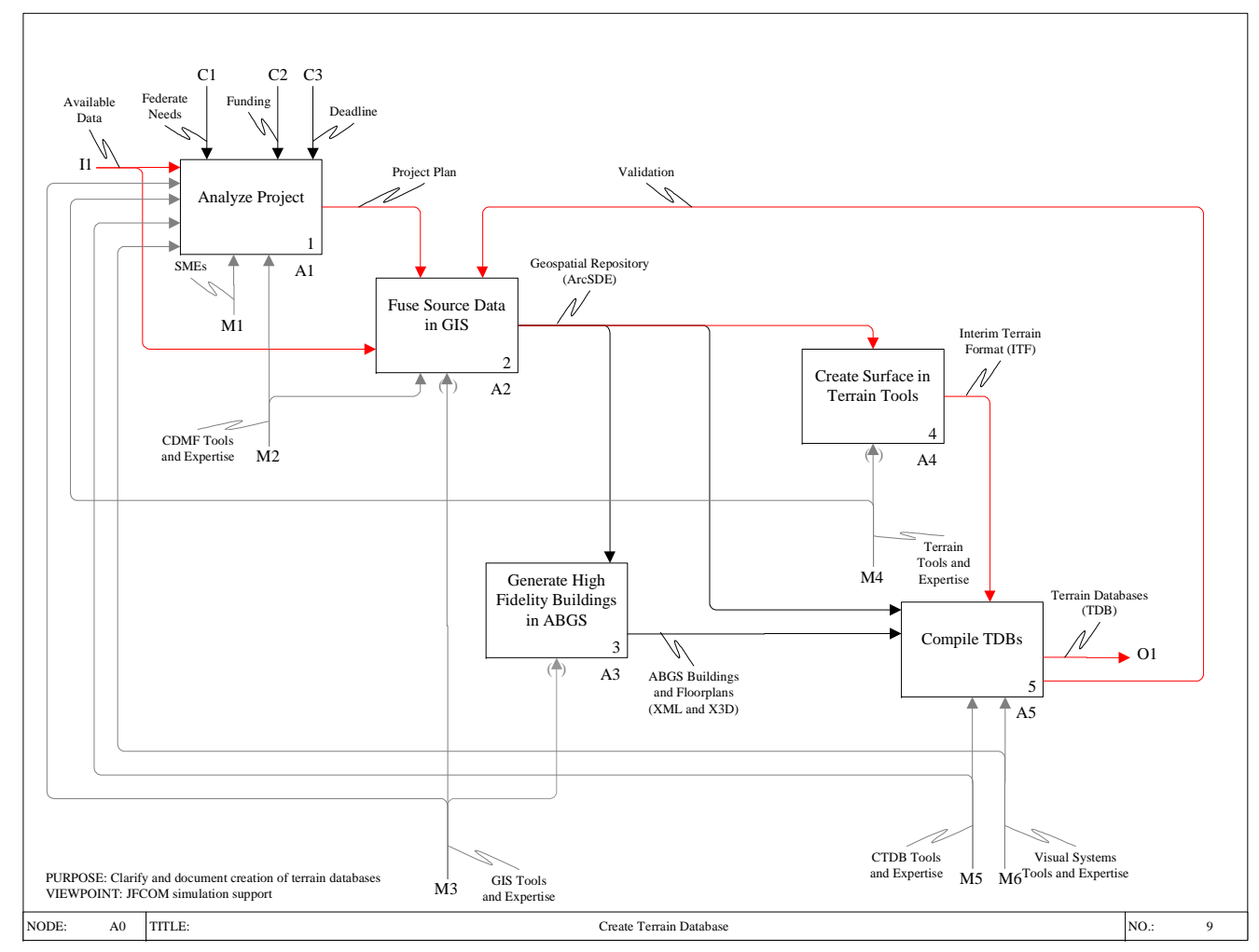
textured database (in Graphic Data Engine format) allowing realistic 3D rendering in J 9 ModStealth. ModStealth is a J SAF-based framework to drive the OpenScene image generator.

Dynamic Terrain (DT) capabilities build directly upon the ITF format, CTDB, and ABGS building formats. Also, ITF may be processed to initialize Multi-State Object databases. Which formats are included depend upon the desired DT functionality. 


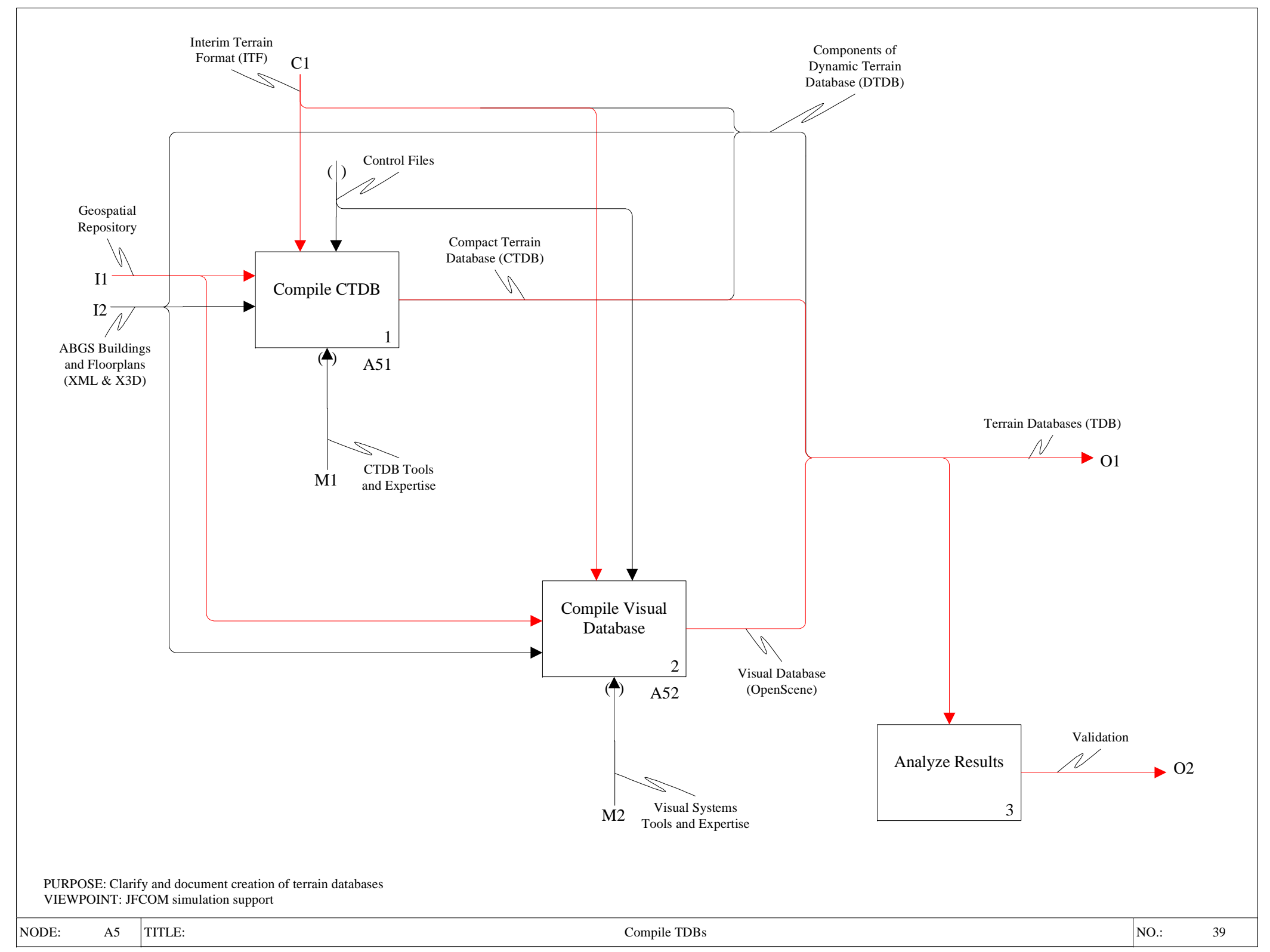




\section{A51 Compile CTDB}

Control files guide and customize the automated compilation of CTDB from GIS features in the repository and ITF databases. The automated procedures integrate the compilation steps, but this node diagram attempts to provide a logical overview of the functions performed.

Compiling a CTDB involves five steps:

(1) translating the surface from ITF to CTDB, (2) adding a third dimension to ground $2 \mathrm{D}$ features, (3) extruding buildings, (4) integrating 3D features and models into the CTDB surface, and (5) generating topology.

2D features should not float in the air or dig through the earth. Grounding them in an appliqué style places them upon the surface of the earth. Points representing locations for the placement of 3D models must also be placed on the surface.

After 2D building footprints have been given Z (elevation) attributes, the extruded structures may be appropriately created in 3D space. Extrusion in the compiler will only occur for buildings not previously processed in the ABGS.

CTDB Format 8 includes "abstract" features, "physical" features, and topology. Physical features tend to be those upon which behaviors are based. The generation of topology facilitates route-based behaviors such as finding the shortest path along a road network from one location to the next. 


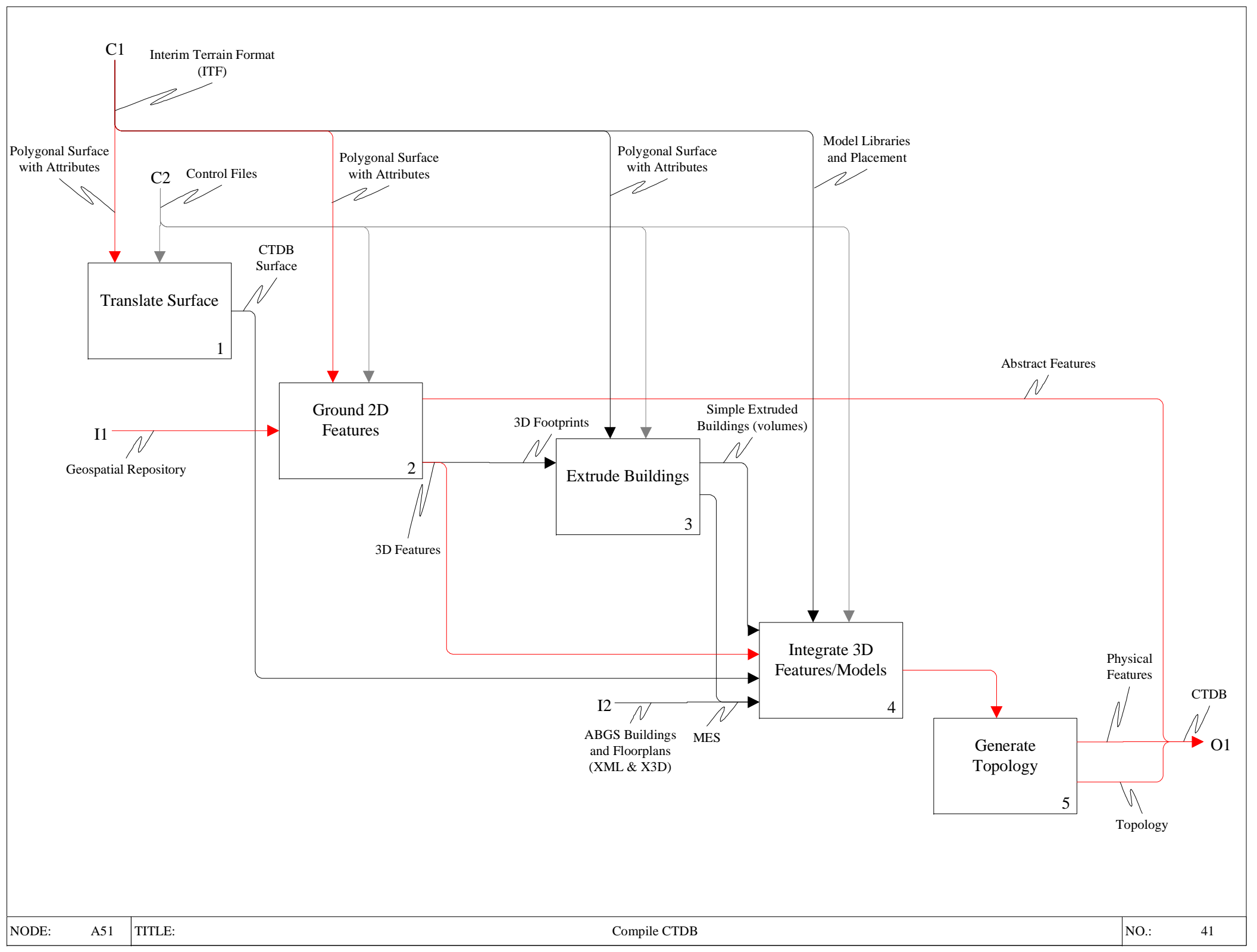




\section{A52 Compile Visual Database}

Compiling a visual database is similar in many respects to creating a CTDB. The primary difference is the inclusion of textures for 3D visualization.

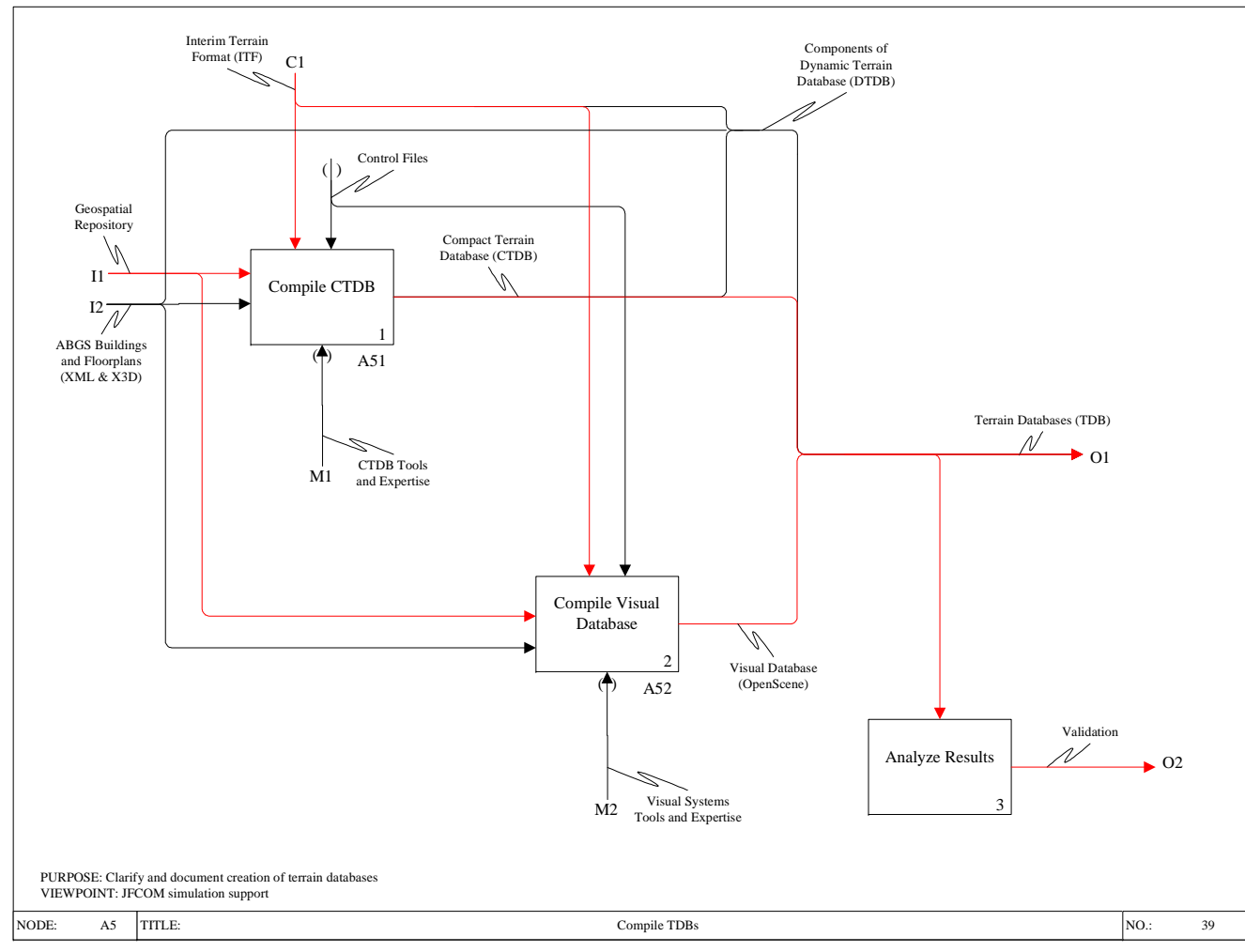




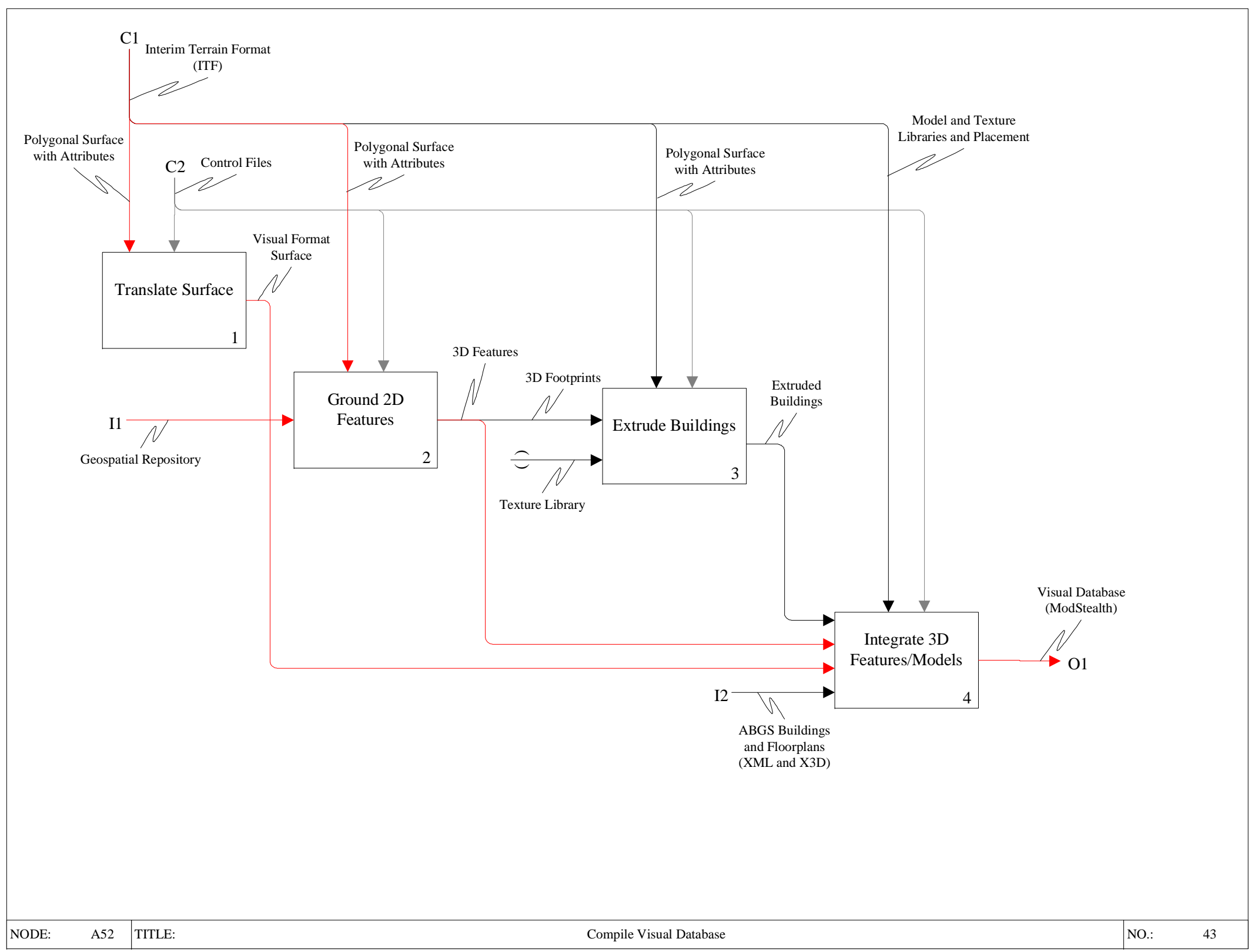




\section{Glossary}

\section{ABGS}

Acronym for Automated Building Generation System. ABGS is an automated building generation software program developed by Lockheed Martin Simulation, Training, and Support.

\section{AOI}

Acronym for Area of Interest. The extent used to define a focus area for either a map or database production.

\section{ArcSDE}

Technology for managing geographic information in a relational database management system (RDBMS). ArcSDE is part of the ArcGIS platform, and is the data server between ArcGIS and relational databases. It is widely used to enable geographic information to be shared by many users across a network and to scale in size from personal, to workgroup, to enterprise use.

\section{Attributes}

Non-spatial information about a geographic feature in a GIS, usually stored in a table and linked to the feature by a unique identifier. For example, attributes of a river might include its name, length, and sediment load at a gauging station. In raster datasets, information associated with each unique value of a raster cell.

\section{Cell}

The smallest unit of information in raster data, usually square in shape. In a map or GIS dataset, each cell represents a portion of the earth, such as a square meter or square mile, and usually has an attribute value associated with it, such as soil type or vegetation class. A pixel.

\section{Clip}

A command that extracts features from one feature class that reside entirely within a boundary defined by features in another feature class.

\section{Data Dictionary}

A catalog or table containing information about the datasets stored in a database. In a GIS, a data dictionary might contain the full names of attributes, meanings of codes, scale of source data, accuracy of locations, and map projections used. 


\section{Data Model}

In GIS, a mathematical construct for representing geographic objects or surfaces as data. For example, the vector data model represents geography as collections of points, lines, and polygons; the raster data model represents geography as cell matrixes that store numeric values; and the TIN data model represents geography as sets of contiguous, non-overlapping triangles. In information theory, a description of the rules by which data is defined, organized, queried, and updated within an information system (usually a database management system).

\section{DEM}

Acronym for Digital Elevation Model. The representation of continuous elevation values over a topographic surface by a regular array of zvalues, referenced to a common datum. DEMs are typically used to represent terrain relief. Also, a DEM is a format for elevation data, tiled by map sheet, produced by the National Mapping Division of the United States Geological Survey (USGS).

\section{Feature}

A representation of a real-world object on a map.

\section{Point feature}

In ArcGIS software, a digital map feature that represents a place or thing that has neither length nor area at a given scale. A map feature that has neither length nor area at a given scale, such as a city on a world map or a building on a city map.

\section{Line feature}

A map feature that has length but not area at a given scale, such as a river on a world map or a street on a city map.

\section{Polygon feature}

In ArcGIS software, a digital map feature that represents a place or thing that has area at a given scale. A polygon feature may have one or more parts. For example, a building footprint is typically a polygon feature with one part. If the building has a detached unit, it might be represented as a multipart feature with discontinuous parts. If the detached unit is in an interior courtyard, the building might be represented as a multipart feature with nested parts. A multipart polygon feature is associated with a single record in an attribute table.

\section{Feature Dataset}

In ArcGIS, a collection of feature classes stored together that share the 
same spatial reference; that is, they share a coordinate system, and their features fall within a common geographic area. Feature classes with different geometry types may be stored in a feature dataset.

\section{Geographic Coordinate System}

A reference system that uses latitude and longitude to define the locations of points on the surface of a sphere or spheroid. A geographic coordinate system definition includes a datum, prime meridian, and angular unit.

\section{GIS}

Acronym for geographic information system. An integrated collection of computer software and data used to view and manage information about geographic places, analyze spatial relationships, and model spatial processes. A GIS provides a framework for gathering and organizing spatial data and related information so that it can be displayed and analyzed.

\section{Image}

A representation or description of a scene, typically produced by an optical or electronic device, such as a camera or a scanning radiometer. Common examples include remotely sensed data (for example, satellite data), scanned data, and photographs. In ArcGIS, a raster dataset.

\section{ModStealth}

ModStealth is J SAF-based framework to drive the nOpenScene image generator.

\section{Projection}

method by which the curved surface of the earth is portrayed on a flat surface. This generally requires a systematic mathematical transformation of the earth's graticule of lines of longitude and latitude onto a plane. Some projections can be visualized as a transparent globe with a light bulb at its center (though not all projections emanate from the globe's center) casting lines of latitude and longitude onto a sheet of paper. Generally, the paper is either flat and placed tangent to the globe (a planar or azimuthal projection) or formed into a cone or cylinder and placed over the globe (cylindrical and conical projections). Every map projection distorts distance, area, shape, direction, or some combination thereof. 


\section{Spatial Reference}

In ArcGIS, the coordinate system, tolerance, and resolution used to store a spatial dataset.

\section{Terrain}

An area of land having a particular characteristic, such as sandy terrain or mountainous terrain.

\section{Texture}

In 3D GIS, a digital representation of the surface of a feature.

\section{TIN}

Acronym for triangulated irregular network. A vector data structure that partitions geographic space into contiguous, nonoverlapping triangles. The vertices of each triangle are sample data points with $\mathrm{x}^{-}, \mathrm{y}^{-}$, and $\mathrm{z}$-values. These sample points are connected by lines to form $\mathrm{De}-$ launay triangles. TINs are used to store and display surface models.

\section{Topology}

In geodatabases, the arrangement that constrains how point, line, and polygon features share geometry. For example, street centerlines and census blocks share geometry, and adjacent soil polygons share geometry. Topology defines and enforces data integrity rules (for example, there should be no gaps between polygons). It supports topological relationship queries and navigation (for example, navigating feature adjacency or connectivity), supports sophisticated editing tools, and allows feature construction from unstructured geometry (for example, constructing polygons from lines).

\section{UTM}

Acronym for Universal Transverse Mercator. A projected coordinate system that divides the world into 60 north and south zones, 6 degrees wide.

\section{Validation}

The process, using formal methods, of evaluating the integrity and correctness of data or a measurement. In modeling, validation is the evaluation of a method to show whether it is assessing the parameter of interest rather than something else.

\section{Vector data}

A coordinate-based data model that represents geographic features as points, lines, and polygons. Each point feature is represented as a sin- 
gle coordinate pair, while line and polygon features are represented as ordered lists of vertices. Attributes are associated with each vector feature, as opposed to a raster data model, which associates attributes with grid cells.

\section{Validation}

The process, using formal methods, of evaluating the integrity and correctness of data or a measurement. The process of comparing the topology rules against the features in a dataset. Features that violate the rules are marked as error features. Topology validation is typically performed after the initial topology rules have been defined, after the feature classes have been modified, or if additional feature classes or rules have been added to the map topology. In modeling, validation is the evaluation of a method to show whether it is assessing the parameter of interest rather than something else.

\section{Verification}

The process, using formal methods, of evaluating a system or software component to determine whether it satisfies the requirements imposed at the start of development.

\section{W3C}

Acronym for World Wide Web Consortium. W3C is an organization that develops standards for the World Wide Web and promotes interoperability between Web technologies, such as browsers, programming languages, and devices. Members from around the world contribute to standards for XML, SOAP, HTML, and many other Web-based protocols.

\section{XML}

Acronym for Extensible Markup Language. Developed by the W3C, $\mathrm{XML}$ is a standardized general purpose markup language for designing text formats that facilitates the interchange of data between computer applications. XML is a set of rules for creating standard information formats using customized tags and sharing both the format and the data across applications. 


\section{Acronyms}

\begin{tabular}{|c|c|}
\hline Term & Spellout \\
\hline 2D & 2-Dimensional \\
\hline $3 \mathrm{D}$ & 3-Dimensional \\
\hline ABGS & Automated Building Generation System \\
\hline $\mathrm{AOI}$ & Areas of Interest \\
\hline ArcSDE & ArcGIS Spatial Database Engine \\
\hline CDMF & Common Data Model Framework \\
\hline CTDB & Compact Terrain Database \\
\hline DEM & Digital Elevation Models \\
\hline DT & Dynamic Terrain \\
\hline DTDB & Dynamic Terrain Database \\
\hline EDM & Environmental Data Model \\
\hline ERDC & Engineer Research and Development Center \\
\hline ESRI & Environmental Systems Research Institute \\
\hline FCS & Future Combat Systems \\
\hline GIS & Geographic Information System \\
\hline IDEFØ & Definition for Function Modeling \\
\hline ITF & Interim Terrain Format \\
\hline JSAF & Joint Semi-Automated Forces \\
\hline MES & Multi-Elevation Structures \\
\hline$M \& D C 2$ & Dismount Command and Control \\
\hline M\&S & Modeling and Simulation \\
\hline SRF & Spatial Reference Frame \\
\hline TDB & Terrain Database \\
\hline TEC & Topographic Engineering Center \\
\hline TIN & Triangulated Irregular Network \\
\hline TSGA & Terrain Scenario Generation and Archiving \\
\hline UTM & Universal Transverse Mercator \\
\hline UTZ & Urban Terrain Zones \\
\hline X3D & $\begin{array}{l}\text { X3D is a data file format used in the Automated Building Generation System } \\
\text { (ABGS) process. }\end{array}$ \\
\hline XML & Extensible Markup Language \\
\hline
\end{tabular}




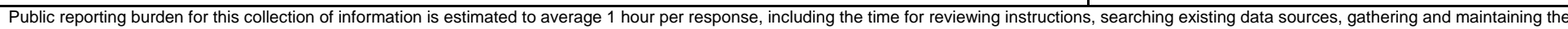

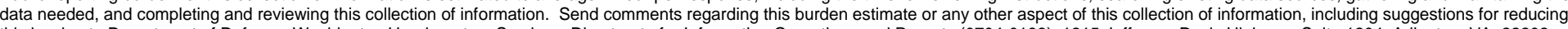

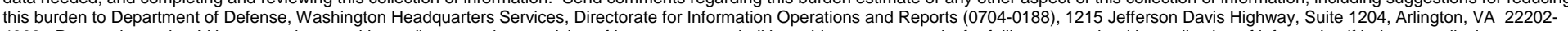

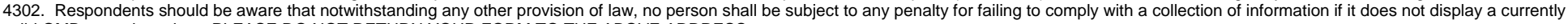
valid OMB control number. PLEASE DO NOT RETURN YOUR FORM TO THE ABOVE ADDRESS.
1. REPORT DATE (DD-MM-YYYY) 19-09-2008

\section{REPORT TYPE} Final

\begin{tabular}{c} 
2. REPORT TYPE \\
Final \\
\hline
\end{tabular}

\section{TITLE AND SUBTITLE}

Functional Decomposition of Modeling

and Simulation Terrain Database

Generation Process:

Using Integration Definition for Function Modeling (IDEFØ)

\section{AUTHOR(S)}

Valerie Raybold Yakich and J. David Lashlee

\author{
(1)
}

Modeling (IDEFØ)

\section{DATES COVERED (From - To)}

5a. CONTRACT NUMBER

5b. GRANT NUMBER

5c. PROGRAM ELEMENT

5d. PROJECT NUMBER

5e. TASK NUMBER

5f. WORK UNIT NUMBER

8. PERFORMING ORGANIZATION REPORT NUMBER

ERDC/TEC SR-08-1

Topographical Engineering Center (TEC)

7701 Telegraph Road,

Alexandria, VA 22135-3864

\section{SPONSORING / MONITORING AGENCY NAME(S) AND ADDRESS(ES)}

U.S. Army Corps of Engineers (USACE)

441 G Street, NW

Washington, DC 20314-1000

11. SPONSOR/MONITOR'S REPORT NUMBER(S)

12. DISTRIBUTION I AVAILABILITY STATEMENT

Approved for public release; distribution is unlimited.

\section{SUPPLEMENTARY NOTES}

\section{ABSTRACT}

The construction of terrain databases is a complex and dynamic procedure. Every terrain database addresses a unique set of simulation federate needs and data availability. This report documents the conceptual procedure as implemented by Lockheed Martin Simulation, Training, and Support and decomposes terrain database construction using the Integration Definition for Function Modeling (IDEFØ). This report includes sufficient detail to conceptually describe the process and provide a foundation for discussion of new and existing terrain database construction efforts among stakeholders with varying levels of technical expertise.

\section{SUBJECT TERMS}

Database management, DEFØ, geospatial data, simulation modeling

\section{SECURITY CLASSIFICATION OF:}

\section{a. REPORT}

Unclassified

\section{b. ABSTRACT}

Unclassified

\section{c. THIS PAGE}

Unclassified
17. LIMITATION OF ABSTRACT

SAR
18. NUMBER OF PAGES

60 19a. NAME OF RESPONSIBLE PERSON

19b. TELEPHONE NUMBER (include area code) 